\title{
Seismic Analysis of Base Isolated Buildings
}

\author{
A.H. Barbat \\ Departamento de Resistencia de Materiales y Estructuras en la Ingeniería \\ E.T.S. Ingenieros de Caminos, Canales y Puertos \\ Universidad Politécnica de Cataluña, Campus Norte UPC, 08034 Barcelona, Spain \\ L.M. Bozzo \\ Departamento de Arquitectura e Ingeniería de la Construcción \\ Escuela Politécnica Superior \\ Universidad de Girona, 17071 Girona, Spain
}

\begin{abstract}
Summary
This paper presents a survey of the numerical simulation of base isolation systems for the vibration control of buildings and their equipment, primarilly against earthquakes. Base isolation has received much attention in the recent twenty years and many buildings have been protected using this technology. The article focusses mainly on the different numerical methods used in the analysis of base isolated buildings. The conventional form of solving the equations of motion governing the seismic response of building structures with nonlinear base isolation consists of using monolithic step by step integration methods. As an efficient alternative static condensation and block iterative schemes can be applied. The particularities of the equations of motion of buildings equiped with various base isolation systems are described. The linear theory of base isolated buildings is then presented. After this, numerical solution techniques for the analysis of the seismic response of buildings with isolation systems are developed in detail in the paper. Finally, numerical results for elastic and inelastic structures are described. A complete set of references coverning a wide range of studies is included
\end{abstract}

\section{INTRODUCTION}

Traditional seismic design of buildings is founded on structural ductility and redundancy. Forces induced by severe earthquakes are reduced as a function of the energy dissipation capacity at the structural components and their connections. Global ductility in a structure is achieved by local and material plasticity of the subsystems. A sound earthquake resistant design guarantees that local and material ductility are not exceeded at a certain level of global ductility demand. Due to uncertainties and nonlinearities it is difficult to estimate the local ductility demands and therefore traditional seismic design provides conservative global minimum requirements for reinforcement ratios, confinement reinforcement and for other design parameters. Besides, nonstructural damage is very difficult to avoid in a conventional seismic design since dynamic forces considerably exceed code design forces. In the recent twenty years, a number of external energy dissipation devices and base isolation devices has been proposed to localize the ductility or to shift the natural frecuencies of a building. This article presents a complete review of base isolation systems in particular regarding their modeling, behaviour and numerical analysis.

Figure 1 illustrates the basic process of selecting the design lateral loads for earthquake resistant buildings. The base shear coefficient $C_{s}$ is defined as the ratio of the total lateral forces $V$ and the total weight of the structure $W$, and in the figure it is presented as a function of the fundamental period of a building. The difference between the loads induced by a severe earthquake and the code design loads is permited only as a function of the ductility and redundancy of the structure. By the contrary, the loads induced by a severe earthquake on a base isolated building are smaller than actual code requirements. This fact is particularly important taking into account that isolated buildings respond in the linear elastic range without plastification of nonstructural and structural components. 


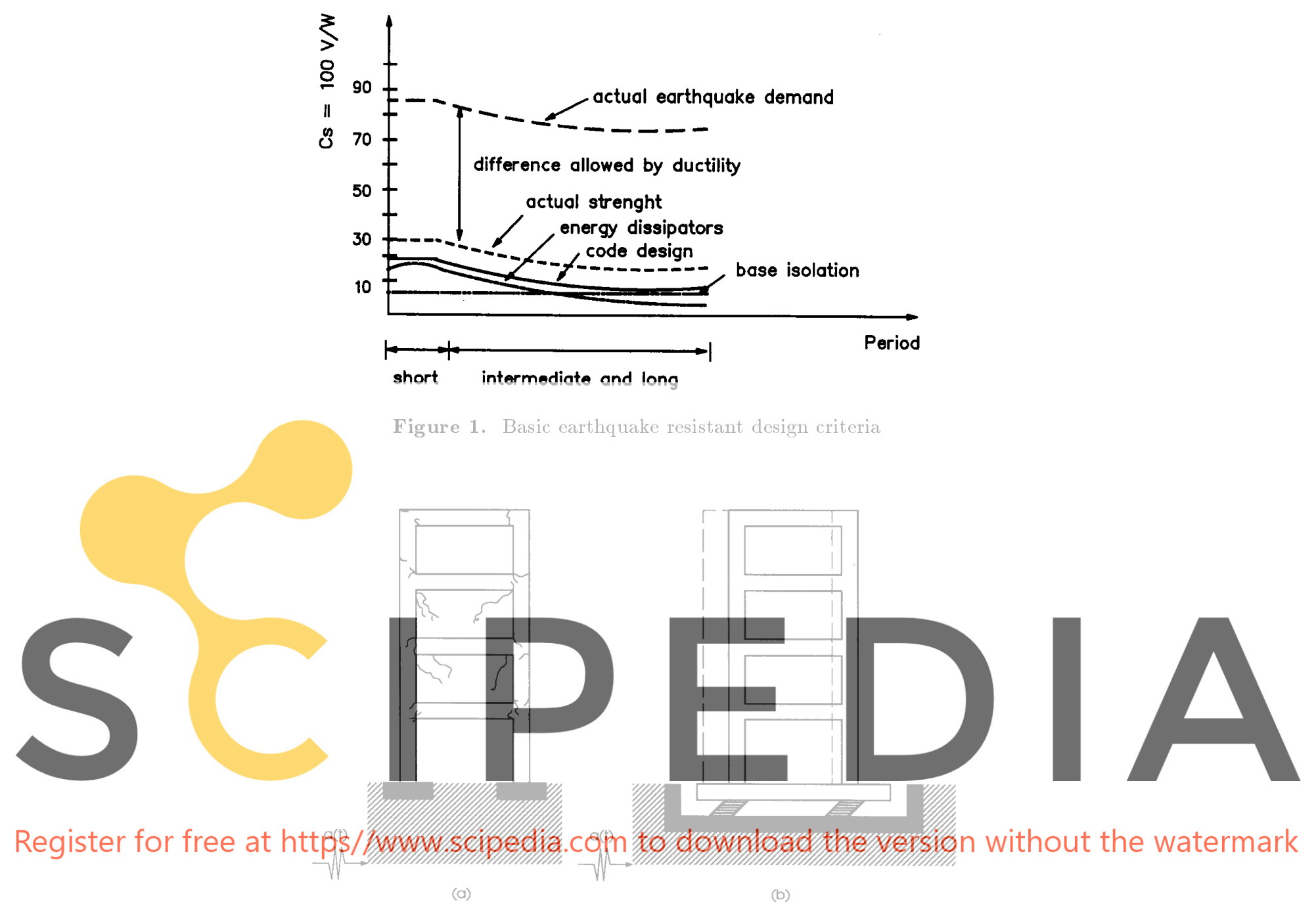

Figure 2. (a) Conventional fix-base building. (b) Base isolated building

Base isolation systems partially uncouple a structure from the seismic ground motion by means of specially designed, replaceable, devices inserted between the structure and its foundation. Figure 2 illustrates a conventional fix-base building and a protected base isolated one. The conventional building reduces dynamic forces by plasticity of the structural and nonstructural components. The protected building reduces dynamic forces by two basic mechanisms: (1) a sliding layer made of a low friction material and (2) a flexible layer made of a rubber material. The first mechanism corresponds to a friction or sliding base isolation system. The main parameter in this case is the friction coefficient. The dynamic forces are reduced by the sliding layer since as the friction coefficient is reduced the dynamic forces are also reduced. The second mechanism corresponds to a rubber base isolation system. The main parameters in this case are the isolator period and its damping coefficient. The dynamic forces are reduced by a period shift since the flexible layer modifies the fundamental period of the building, ideally far from the fundamental period of earthquakes.

Even though the serious study of base isolation is a recent subject, there is a number of old historic buildings protected with some kind of isolation. Kirikov (1992) describes various 
procedures used by Sumerians, Greeks, Romans and Byzantins, among others, to protect their structures against earthquakes. The most usual earthquake protection systems was to place a layer of thin sand below the foundations in order to obtain a "sliding isolation" system. This technique was applied by the Knossos builders in Creta, 2000 years b.c. in various buildings and even in their famous palace. Similar techniques have been used by the greeks in Chokrak, in the coast of the sea of Azov. The foundations of their temple, built in the III century b.c., has a layer of sand and two layers of small and medium size rocks. In this century Jacob Bechtold from Munich, Germany, presented a patent in the United States for an earhquake resistant building (Buckle and Mayes 1990). Bechtold proposed to support buildings using a rigid base and spheric rollers. In 1909 a doctor from Scarborough, England, presented a patent in England for a support system made of talc powder layers. In 1929, Robert Wladislas de Montalk from Wellington, New Zeland, presented a patent for a building supported on springs that absorb or minimize impacts.

It is clear that sliding isolation is the most intuitive technique to perform dynamic isolation. The basic sliding isolation mechanism is to limit the force transmited from the foundation to the building. Consequently, it is not surprising that various systems have been proposed in this century using metal rollers. A different and older use of sliding plates is in bridges, in order to minimize stresses caused by thermal expansions. The difference with sliding base isolation of buildings against earthquake effects is that the sliding plates in bridges often move, since thermal dilations occur frecuently. In sliding isolation the plates may stick to each other increasing the friction coefficient with time (Kelly 1986).

The first use of elastomers in base isolation took place in 1969 in Scopje, Macedonia for a three story building (Kelly 1986). This building was supported on plain elastomers. Due to its reduced vertical and horizontal stiffness the building rocked and this system has never been used ag a earthquake forces using en predominat period of a the fundamental period, reinforced neopréne pads,
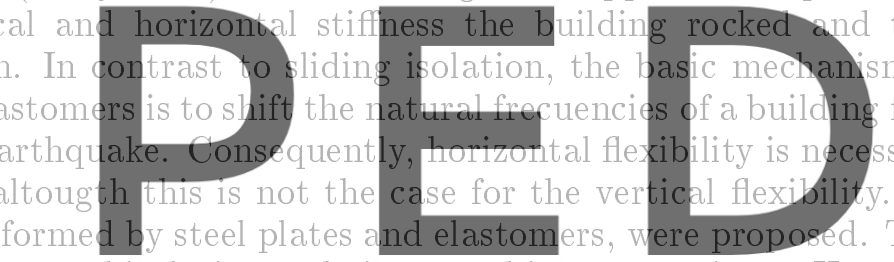

is probably the most wide spread isolation technique used in present times. However, sliding

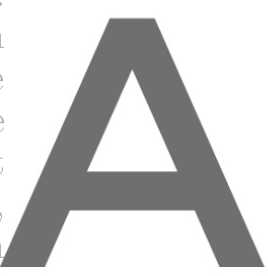

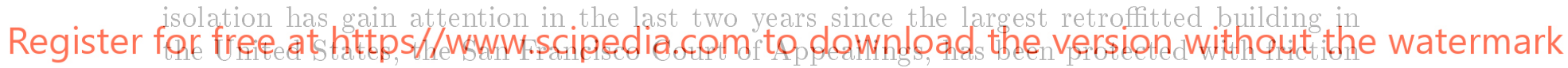
base isolation (Amin and Mokha 1995).

\section{SYSTEMS DESCRIPTION}

Modern base isolation started about twenty five years ago with the introduction of elastomers, in particular the laminated rubber bearings. This is nowadays the most widely used isolation system. As illustrated in Figure 3(a), the laminated rubber bearings are formed by layers of neoprene and steel plates with the rubber being vulcanized to the steel plates. This connection is very flexible in the horizontal direction by stiff in the vertical direction. A structure supported on these connections has a longer period compared to a similar but fix-base structure and the frecuency shift reduces dynamic amplifications (Fan et al. 1988). This reinforced neoprene pads are similar to the ones used in bridges. The experience with bridges allows to ensure their strength and durability even in hard enviroments and fires.

The use of base isolation systems allows to satisfy code requirements without a significant increase in cost. Therefore, these connections have been investigated in many world wide institutions. For example, the "Centre National de la Recherche Scientifique" in Marseille, France, started in 1972 a research project to study the use of these connections for the protection of buildings. The results were applied to various structures (Buckle and Mayes 1990). 


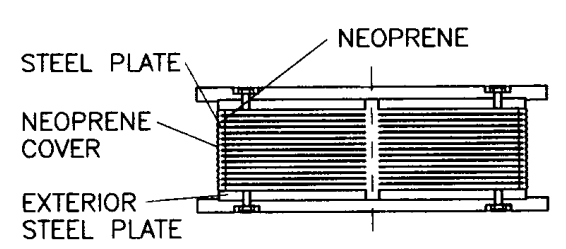

(a)

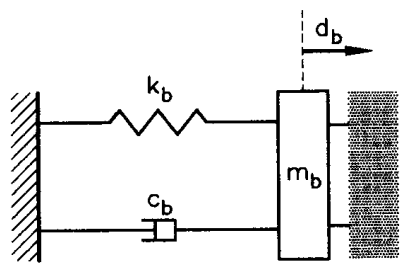

(b)

Figure 3. Laminated rubber bearing. (a) Scheme. (b) Dynamic model

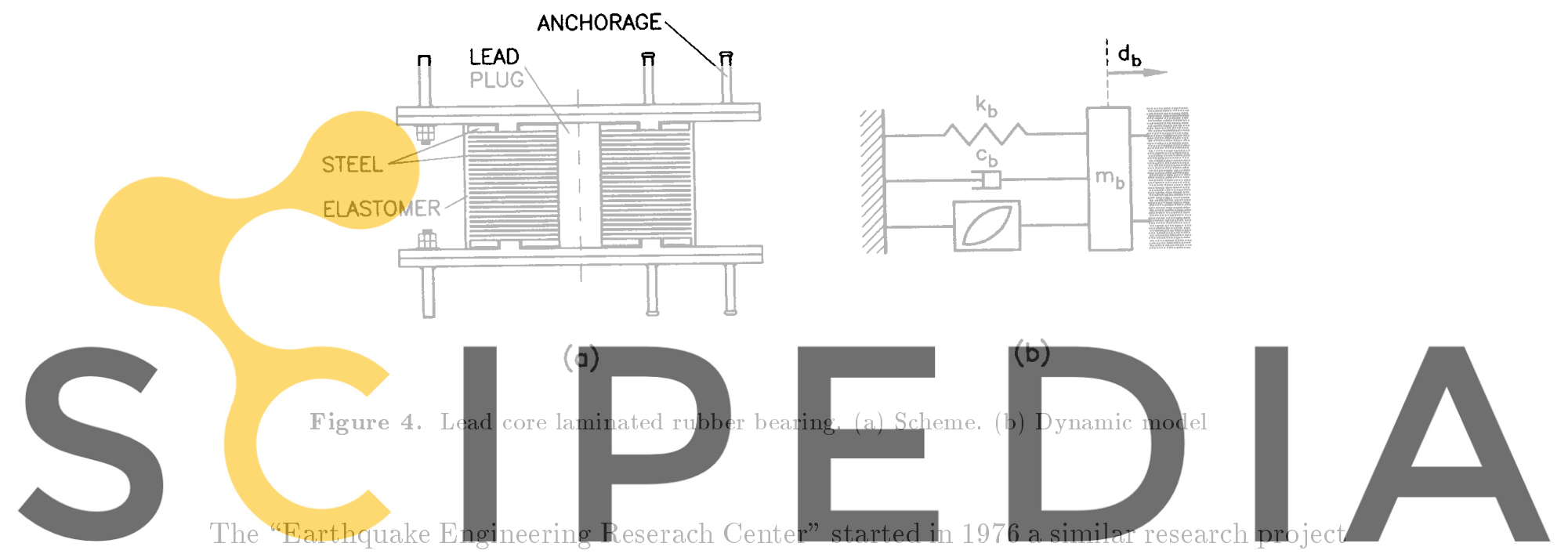

in the University of California at Berkeley (Kelly 1980; Kelly and Beucke 1983; Kelly 1991b).

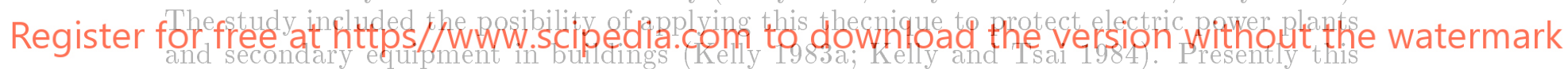
center continues with the experimental study of elastomers (Koh and Kelly 1986; Tajirian et al. 1990a; Tajinian et al. 1990b) comparing its results with numeric simulation (Kelly and Aiken 1989).

The shifting of the fundamental frecuency of a buildings far from the predominat period of an earthquake does not fully guarantees the protection of the structure from a possible resonance with higher natural frecuencies. Besides, various earthquakes do not present a predominant period, but various spectral peaks which may excite the building. Maximum base isolation displacements must also be restrained to certain acceptable levels (Buckle and Mayes 1990). For these reasons it is required to use elastomers with high damping ratio, which dissipate energy at the connections. A system which considerably increases the connection damping was developed in New Zeland (Robinson 1982). The connection, illustrated in Figure 4(a), has a lead core.

The lead core in the reinforced neoprene pads increases the damping ratio from about $3 \%$ to $15 \%$. The mechanical behaviour of this isolation system is equivalent to the one of a nonlinear damper (Skinner et al. 1975). There are theoretical studies about the behaviour of structures supported on this system, as well as shaking table tests. An example of a building constructed with this system is the Clayton Building in Wellington, New Zeland. The "high stability" connections, illustrated in Figure 5, have also been developed in this country (McKay et al. 1990). The system consists of various steel plates separated by neoprene pads placed at the corners. The horizontal stiffness is, consequently, very low, 
maintaining the vertical stability even under large displacements (SMIRT11 1991a; Dowrick et al. 1992).

The high seismicity in Japan has contributed notorioulsy in the development of base isolation systems. Presently, there are more than 58 buildings constructed in that country mainly using laminated rubber bearings with or without the lead core (SMIRT11 1991b). High stability systems have been also studied in Japan (SMIRT11 1991c).

An older approach to base isolation is pure friction. The sismplest idealization for such a system is illustrated in Figure 6(a). In this context the frictional horizontal forces oppose the sliding and dissipate energy (Fan et al. 1988; Mostaghel and Tanbakuchi 1983). Various research projects in the "National Center for Earthquake Engineering Research" in Buffalo, New York, have focuss in the use of teflon (Mokha et al. 1988; Constantinou et al. 1990a). The connection by itself does not have any restitutive force and therefore large remanent displacements may occur. This problem can be solved using curved sliding plates, as illustrated in Figure 7(a). This system, called the "Frictional Pendulum System (FPS)", has been developed in the United Stated in the 80's. The restitutive force in this case is achieved by the weigth of the supported building, minimizing the remanent displacement (Mokha et al. 1990; Zayas et al. 1988; Zayas et al. 1990).

In China there is a construction technique that separates a building from its foundation using a layer of sand. This technique arrised from field observations after the Tang Shan earthquake of 1976. In particular, it was reported that masonry block buildings with a foundation not monolitically constructed to their upper structure, responded better that conventional structures in which the reinforcement was carried through to the foundation. It was concluded that the improvement in response was due to horizontal sliding. This
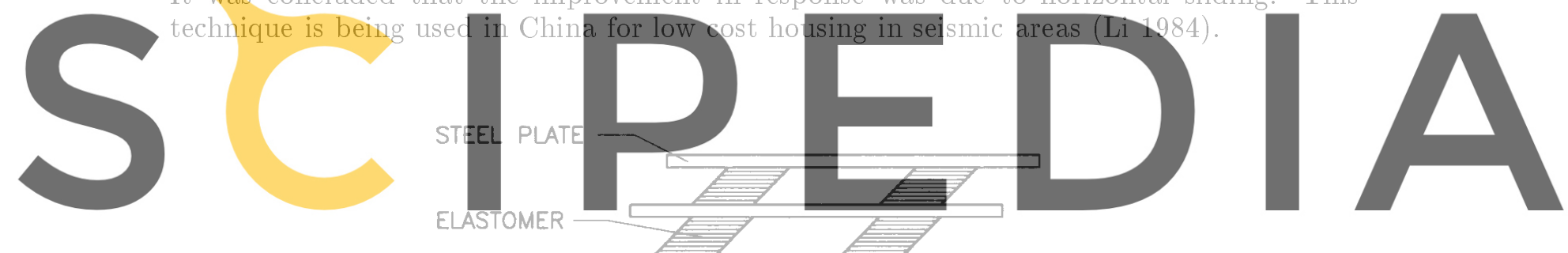

Register for free at https//www.scipedacom to wo the version without the watermark

Figure 5. High stability isolation system

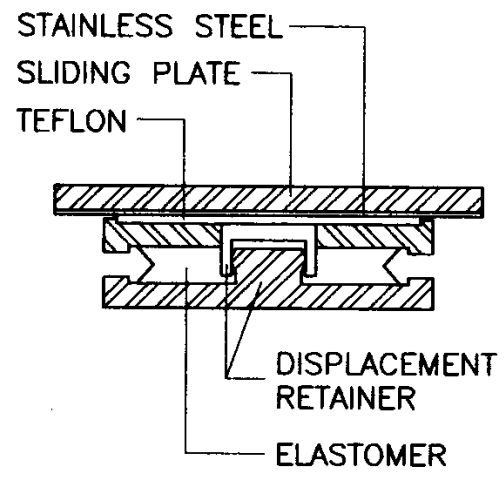

(a)

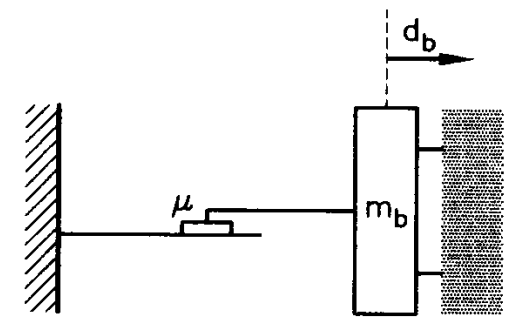

(b)

Figure 6. Friction isolation system. (a) Scheme. (b) Dynamic model 


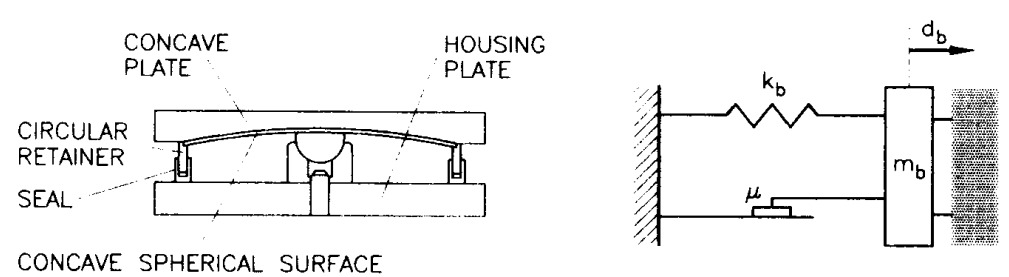

STEEL OVERLAY

(a)

(b)

Figure 7. FPS connection. (a) Scheme. (b) Dynamic model

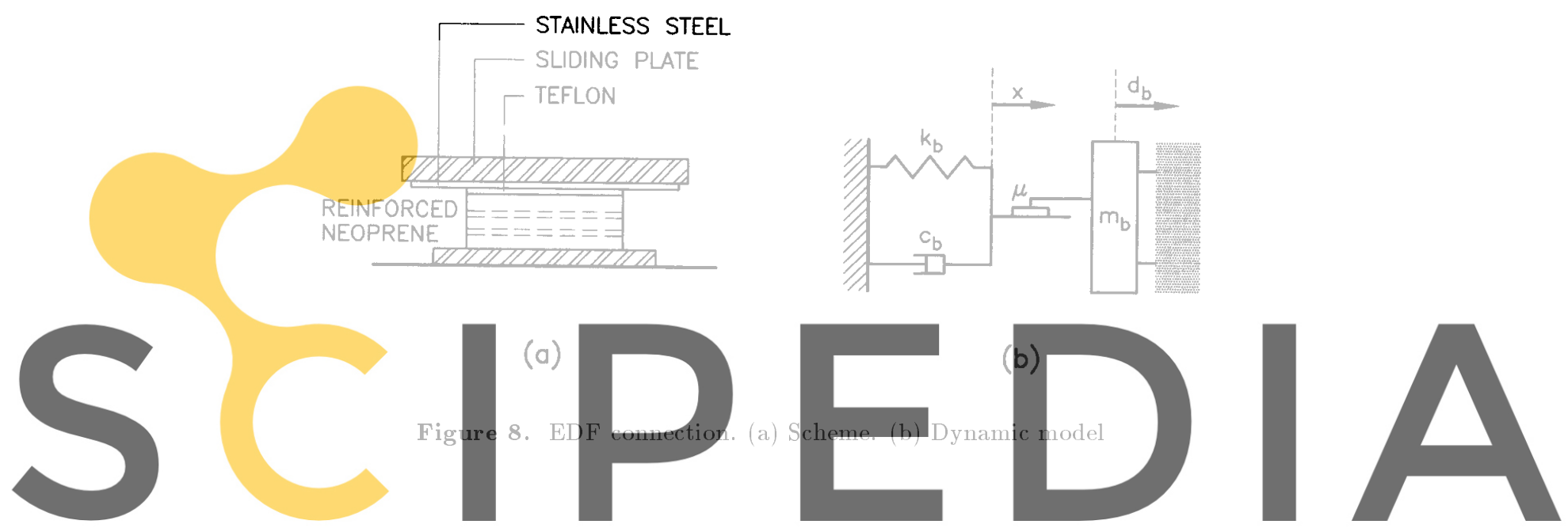

An importat application of base isolation is for nuclear power plants. The protection can

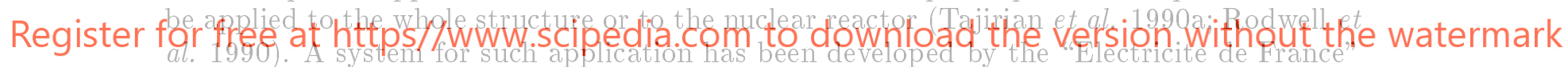
and it is called the EDF system. The connection consists of two sliding steel plates and a neoprene reinforced pad, as illustrated in Figure 8(a). If the structure is affected by a low intensity ground motion, the response is controled by the neoprene pads. If the intensity of the seismic ground motion is increased and sliding takes place, the force transmitted from the foundation to the building is limited by the friction of the plates. Consequently, the sliding plates are for security under extreme earthquakes.

A recently proposed connection is the elastic-frictional one (Mostaghel 1984; Mostaghel et al. 1986; Mostaghel and Khodaverdian 1987). The systems is made of various teflon coated steel plates and a neoprene nucleous, as illustrated in Figure 9(a). The neoprene provides the necesary restoring force to keep the remanent displacements under acceptable limits and the sliding plates dissipate energy by friction (Mostaghel and Khodaverdian 1988; Mostaghel and Kelly 1987). Other elastic-frictional support systems are described by Ikonomou (1985), Caspe and Reinhorn (1986) and Nagashima et al. (1987).

Another isolation system uses the combined action of the elastic-frictional system and of the EDF one. The connection is as the elastic-frictional one but there are sliding plates joining it to the upper structure. Consequently, for low intensity actions, the system behaves as the elastic-frictional one. As the intensity increases, the sliding of the upper plates uncouple the structure from the ground displacements. There is no mechanism to limit the remament sliding displacement. However, the friction coefficient is high and sliding is activated only under extreme events. 


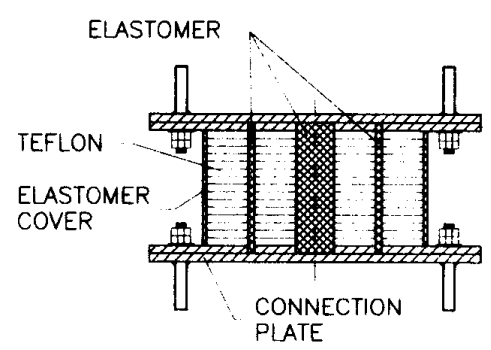

(o)

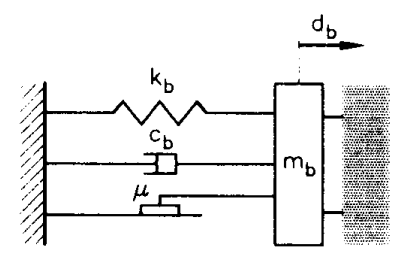

(b)

Figure 9. Elastic-frictional connection. (a) Scheme. (b) Dynamic model

A phenomenon that need to be taken into account is the vertical uplift of the supports. This situation is caused by moments induced by lateral actions. Experimental studies are reported by Griffith et al. (1988a), Griffith et al. (1988b) and Griffith et al. (1990a). As a result, it is not recomendable to design slender structures, altougth there are studies about how to resist these uplift forces (Griffith et al. 1990b).

Base isolation was originally intended for new buildings, however, its application has been extended to rehabilitation of old ones (Kelly 1983b). Seismic upgrade of old hystoric buildings using conventional techniques may cause a substantial modification of the building, besides its elevated cost. In the USA this technique has been employed for the retrofitting of the Salt Lake City and County Building, the Masonic Hall both in Salt Lake City, Utah (Kelly 1983b) and the Mackay School of Mines in Reno, Nevad (Way and Howard 1992; Way and Howard 1990 heavier retrofitted building in the system (Keowen et al. 19

Finally, Kwok (198 $)$ buildings constructed i
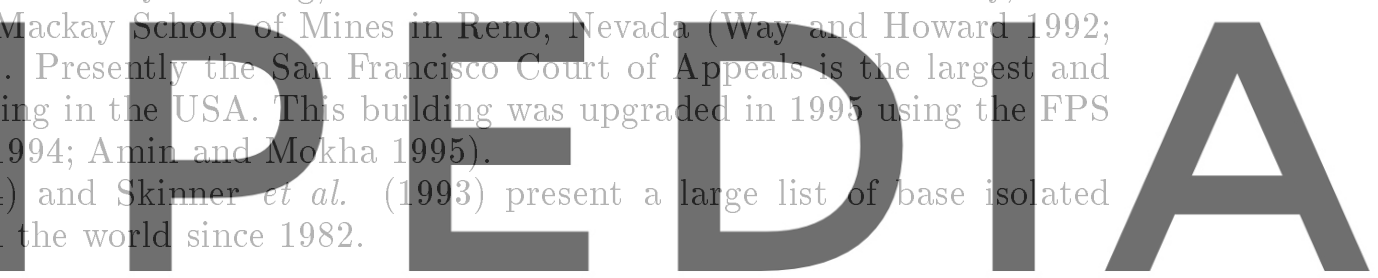

3 GOVERNING EQUATIONS. Register for free at https//www.scipedia.com to download the version without the watermark

The design of base isolated structures aims to maintain the building structure in the linear elastic range, concentrating the nonlinearities at the base. Considering the notation presented in Figure 10, the equation of motion for such a system subjected to an earthquake excitation $a(t)$ is given as

$$
\boldsymbol{M} \ddot{\boldsymbol{D}}+\boldsymbol{C} \dot{\boldsymbol{D}}+\boldsymbol{K} \boldsymbol{D}=-\boldsymbol{M} \boldsymbol{J}\left[\ddot{d}_{\mathrm{b}}+a\right]
$$

where $\boldsymbol{D}$ is a vector representing the story displacements relative to its base, $d_{\mathrm{b}}$ is the displacement of the base relative to the ground, $\boldsymbol{M}$ is the mass matrix, $\boldsymbol{C}$ is the damping matrix, $\boldsymbol{K}$ the stiffness matrix and $\boldsymbol{J}$ is the vector that relates the rigid body motion to the degrees of freedom of the model. For shear buildings, $\boldsymbol{J}$ is equal to the unit vector. The boundary conditions are

$$
\text { For } \quad t=0 \rightarrow D=\mathbf{0}, \quad \dot{D}=\mathbf{0}
$$

The damping and stiffness forces applied from the building to the base are obtained from equation (1) as

$$
\boldsymbol{J}^{\mathrm{T}} \boldsymbol{C} \dot{D}+\boldsymbol{J}^{\mathrm{T}} \boldsymbol{K} \boldsymbol{D}=-\boldsymbol{J}^{\mathrm{T}} \boldsymbol{M} \ddot{\boldsymbol{D}}-\boldsymbol{J}^{\mathrm{T}} \boldsymbol{M} \boldsymbol{J}\left[\ddot{d}_{\mathrm{b}}+a\right]
$$




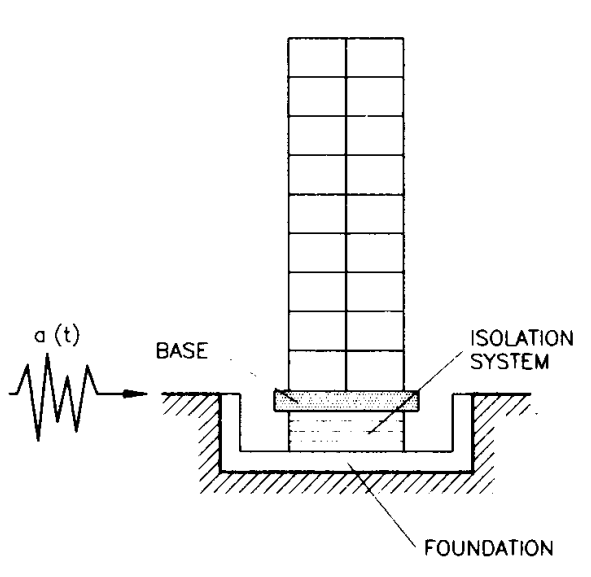

a)

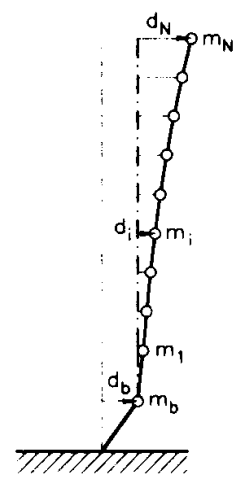

b)

Figure 10. Base isolated building. (a) Scheme. (b) Dynamic model

Consequently, the equation of motion for the base is

$$
m_{\mathrm{b}}\left(\ddot{d}_{\mathrm{b}}+a\right)+\boldsymbol{J}^{\mathrm{T}} \boldsymbol{M}\left[\ddot{D}+\boldsymbol{J}\left(\ddot{d}_{\mathrm{b}}+a\right)\right]+f=0
$$

Here, $m_{\mathrm{b}}$ is the mass

exerted from the base

and the next stibsection

equations (Su et al. 198

1994).

Using mode superposition,
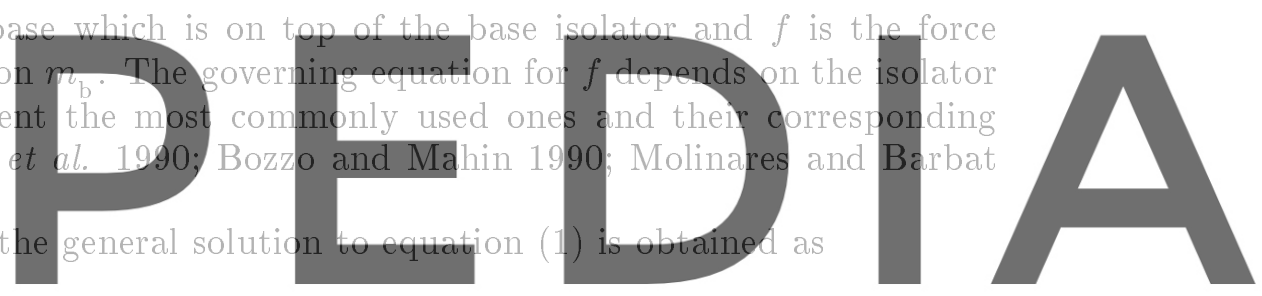

Register for free at https//www.scipedia.comito download the version without the watermark

where $\varphi$, are the mode shapes and $q$ is the number of modes included in the analysis. The modal amplitudes $\eta_{i}$ are determined by

$$
\ddot{\eta}_{i}(t)+2 \nu_{i} \omega_{i} \dot{\eta}_{i}(t)+\omega_{i}^{2} \eta_{i}(t)=-\frac{\varphi_{i}^{\mathrm{T}} \boldsymbol{M} \boldsymbol{J}}{\boldsymbol{\varphi}_{i}^{\mathrm{T}} \boldsymbol{M} \boldsymbol{\varphi}_{i}}\left[\ddot{d}_{\mathrm{b}}+a\right]=Q_{i}\left[\ddot{d}_{\mathrm{b}}+a\right]
$$

Here, $\omega_{i}$ and $\nu_{i}$ are the natural frequencies and damping coefficients of the building and $Q_{i}$ is defined as the modal participation factor. Introducing equation (5) into equation (4), the resulting equation governing the motion of the base mass $m_{\mathrm{b}}$ is

$$
m_{\mathrm{b}}\left(\ddot{d}_{\mathrm{b}}+a\right)+\boldsymbol{J}^{\mathrm{T}} \boldsymbol{M}\left[\sum_{i=1}^{q} \boldsymbol{\varphi}_{i} \ddot{\eta}_{i}(t)+\boldsymbol{J}\left(\ddot{d}_{\mathrm{b}}+a\right)\right]+f=0
$$

In addition, in general, the isolators require diplacement restrainers which limit excessive displacements. From the point of view of the equations of motion, these stops add a further condition to the treatment of the non-linearity. During the time period when the base is stick against the stop, there is no interaction. Obviously, in a well designed isolation device, these stops are not reached for a seismic ground motion within the design range. 


\subsection{Pure-friction Base Isolator}

This is the simplest base isolator and corresponds to a building supported on sliding connections (Mostaghel and Tanbakucci 1983; Kelly and Beucke 1983; Constantinou and Tadjbakhsh 1984; Dorka 1994; Tsopelas and Constantinou 1994). A scheme of this connection and the corresponding dynamic model are presented in Figure 6 . The equation of motion for the base - equation (7) - corresponding to a pure Coulomb constant friction base isolator and assuming that the sliding surfaces are always in contact, is rewritten as

$$
m_{\mathrm{b}}\left(\ddot{d}_{\mathrm{b}}+a\right)+\boldsymbol{J}^{\mathrm{T}} \boldsymbol{M}\left[\sum_{i=1}^{q} \boldsymbol{\varphi}_{i} \ddot{\eta}_{i}(t)+\boldsymbol{J}\left(\ddot{d}_{\mathrm{b}}+a\right)\right]+\mu g m_{\mathrm{tot}} \operatorname{sign}\left(\dot{d}_{\mathrm{b}}\right)=0
$$

Where $g$ is the acceleration of gravity and $\mu$ is the friction coefficient - typical values range from $\mu=0.1$ to $\mu=0.3$ - and $m_{\text {tot }}$ is the total mass above the isolator $m_{\text {tot }}=\boldsymbol{J}^{\mathrm{T}} \boldsymbol{M} \boldsymbol{J}+m_{\mathrm{b}}$. Equation (8) describes the behaviour of the system in the sliding phase. If the base mass sticks to the foundation, the non-sliding condition
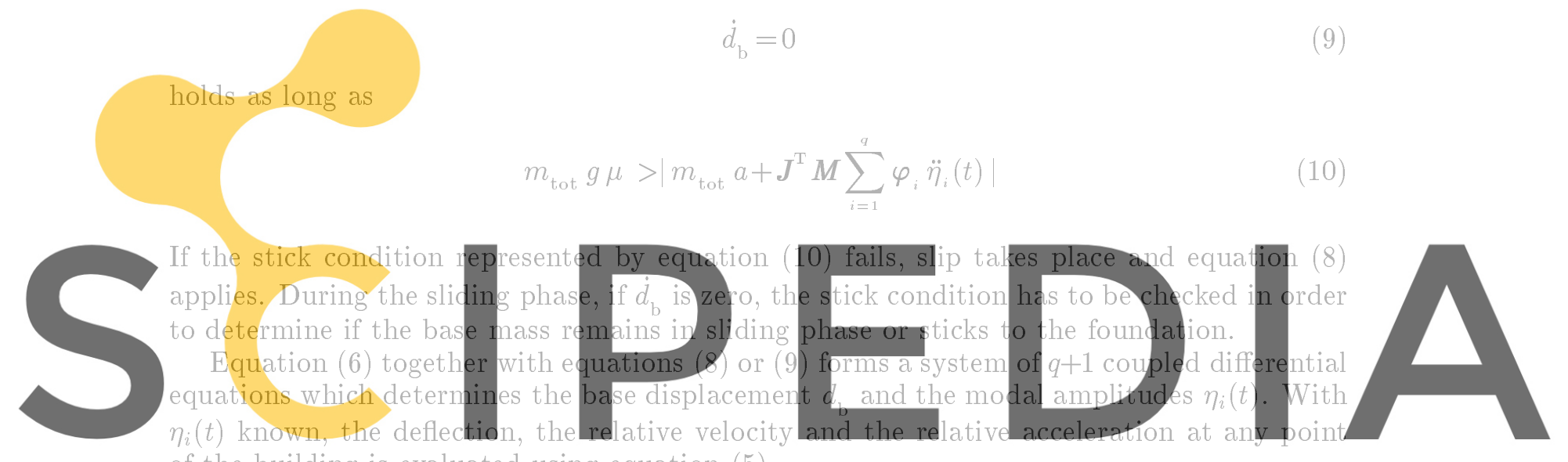

of the building is evaluated using equation (5).

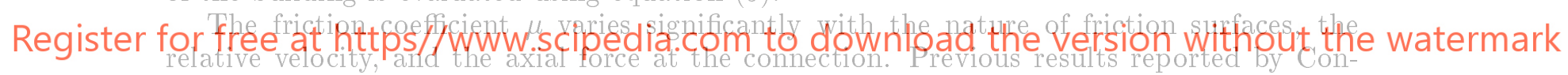
stantinou et al. (1990a) and by Mokha et al. (1988) suggest to model the friction coefficient

ais

$$
\mu=\mu_{\max }-\left(\mu_{\max }-\mu_{\min }\right) \exp \left(-b\left|\dot{d}_{\mathrm{b}}\right|\right)
$$

where $\mu_{\max }$ is the friction coefficient at high sliding velocities, $\mu_{\min }$ is the friction coefficient at velocities near zero, $b$ is a parameter controlling the friction coefficient variation with velocity and $\dot{d}_{\mathrm{b}}$ is the sliding velocity. The parameters involved in the expression are obtained for a given axial pressure at the sliding surface. This velocity dependent model implies that the friction coefficient is a monotonic increasing function of the sliding velocity. In general, the effect of an increment in the axial force is to reduce the friction coefficient.

The effect on response due to variations in the friction coefficient during sliding may be significant, specially for limited strength structures, such as retrofitted ones (Bozzo and Barbat 1995). Variations in ductility demand are not linearly dependent on variation in the friction coefficient.

Another factor that influence the frictional force at a connection is the vertical acceleration, which may change significantly during an earthquake. The frictional force is directly proportional to the reactive weigth $-m_{\text {tot }}$ in equation (8) - which is a function of the instantaneous vertical acceleration. 


\subsection{Frictional Pendulum System (FPS System)}

An scheme of this connection and the corresponding dynamic model is presented in Figure 7. The equation of motion for the base corresponding to a building supported on ideal FPS connections and assuming that the sliding surfaces are always in contact is

$$
m_{\mathrm{b}}\left(\ddot{d}_{\mathrm{b}}+a\right)+\boldsymbol{J}^{\mathrm{T}} \boldsymbol{M}\left[\sum_{i=1}^{q} \boldsymbol{\varphi}_{i} \ddot{\eta}_{i}(t)+\boldsymbol{J}\left(\ddot{d}_{\mathrm{b}}+a\right)\right]+\mu g m_{\mathrm{tot}} \operatorname{sign}\left(\dot{d}_{\mathrm{b}}\right)+k_{\mathrm{b}} d_{\mathrm{b}}=0
$$

where $k_{\mathrm{b}}$ is the effective sliding lateral stiffness (Zayas et al. 1988; Zayas et al. 1989; Bozzo and Mahin 1990). This additional restoring force is provided by metalic springs or by the curvature of the sliding surface in the FPS-system. The sliding lateral stiffness is useful to define the period of the connection $T_{\mathrm{b}}$. This parameter corresponds to the period of a perfectly rigid structure sliding at the connection and it is given by $T_{\mathrm{b}}=2 \pi \sqrt{m_{\mathrm{tot}} / k_{\mathrm{b}}}$. For the FPS system, $T_{\mathrm{b}}=2 \pi \sqrt{r / g}$, where $r$ is the radius of curvature of the sliding surface.

The aforementioned equation (12) describes the behaviour of the system in the sliding phase. Similarly to the pure friction system, if the base mass sticks to the foundation, the non-sliding condition

holds as long as

$$
\dot{d}_{\mathrm{b}}=0
$$

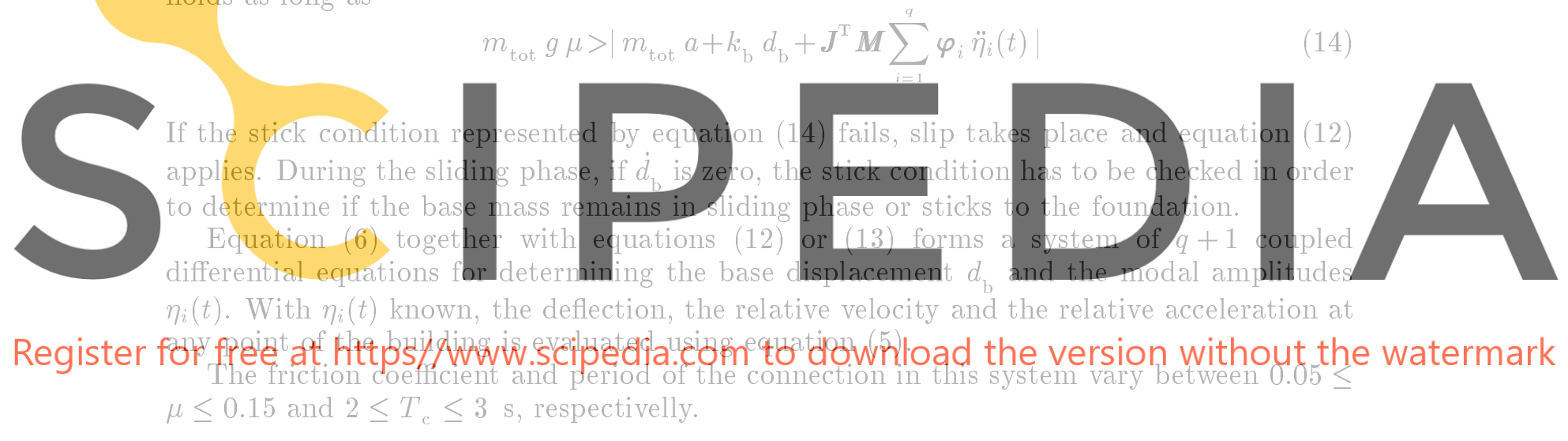

\subsection{Laminated Rubber Bearing Isolator (LRB System)}

An scheme of this connection and the corresponding dynamic model is presented in Figure 3. The equation of motion for the base of a building supported on rubber bearings or viscodampers and excited by a horizontal earthquake ground acceleration $a(t)$ can be represented as

$$
m_{\mathrm{b}}\left(\ddot{d}_{\mathrm{b}}+a\right)+c_{\mathrm{b}} \dot{d}_{\mathrm{b}}+k_{\mathrm{b}} d_{\mathrm{b}}+\boldsymbol{J}^{\mathrm{T}} \boldsymbol{M}\left[\sum_{i=1}^{q} \boldsymbol{\varphi}_{i} \ddot{\eta}_{i}(t)+\boldsymbol{J}\left(\ddot{d}_{\mathrm{b}}+a\right)\right]=0
$$

where $c_{\mathrm{b}}$ is the equivalent damping and $k_{\mathrm{b}}$ is the equivalent stiffness of the base isolator (Kelly 1991a). The equivalent linear system for the isolator enables a simple numeric solution of the problem. The modal amplitudes $\eta_{i}(t)$ and the base displacement $d_{\mathrm{b}}$ are obtained solving the linear system of coupled differential equations given by equations (6) and (15).

A common rubber bearing design period is about $T_{\mathrm{b}}=2 \mathrm{~s}\left(\right.$ where $T_{\mathrm{b}}=2 \pi \sqrt{m_{\text {tot }} / k_{\mathrm{b}}}$ ). The equivalent damping coefficient of the rubber varies considerably. For low strain, it is as high as about $\nu_{\mathrm{b}}=0.3$ (where $\nu_{\mathrm{b}}=c_{\mathrm{b}} / 2 \omega_{\mathrm{b}}$ ) but for high strain it is as low as about 0.05 . A common value used for design is $\nu=0.1$. 
An additional source of instability in rubber bearings, compared to friction base isolation is the potential buckling of the bearings. The large horizontal displacements sustained by the isolators may induce significant secondary $P-\Delta$ moments. The instability is similar to that of a conventional column but dominated by the low-shear stiffness of the bearing (Koh and Kelly 1986; Koh and Balendra 1989; Kelly 1993).

\subsection{Resilient-Friction Base Isolation System (R-FBI System)}

An scheme of this connection and the corresponding dynamic model is presented in Figure 9. The resilient-friction base isolator uses the parallel actions of resiliency of rubber and friction of teflon coated plates. The equation of motion for the base of a building supported on R-FBI isolators can be expressed as

$$
m_{\mathrm{b}}\left(\ddot{d}_{\mathrm{b}}+a\right)+c_{\mathrm{b}} \dot{d}_{\mathrm{b}}+k_{\mathrm{b}} d_{\mathrm{b}}+\mu g m_{\mathrm{tot}} \operatorname{sign}\left(\dot{d}_{\mathrm{b}}\right)+\boldsymbol{J}^{\mathrm{T}} \boldsymbol{M}\left[\sum_{i=1}^{q} \boldsymbol{\varphi}_{i} \ddot{\eta}_{i}(t)+\boldsymbol{J}\left(\ddot{d}_{\mathrm{b}}+a\right)\right]=0
$$

where $c_{\mathrm{b}}$ is the equivalent damping and $k_{\mathrm{b}}$ is the equivalent stiffness of the base isolator and $\mu$ is the friction coefficient.

Equation (16) describes the motion of the base in the sliding phase. Initially when the base stars from rest whenever the friction plates are sticking to each other through the friction force, the non-sliding condition given by equation (9) holds as long as

$$
m_{\text {tot }} g \mu>\left|m_{\text {tot }} a+k_{\mathrm{b}} d_{\mathrm{b}}+\boldsymbol{J}^{\mathrm{T}} \boldsymbol{M} \sum_{i=1}^{q} \boldsymbol{\varphi}_{i} \ddot{\eta}_{i}(t)\right|
$$

If the non-sliding condition given by aforementioned equation is not satisfied, slip takes place and the motion is governed by equation (16). If the relative velocity becomes zero during the sliding phase then the non-sliding condition given by equation (17) must be verified. The verification indicates if the base remains in the sliding phase or sticks to the foundation.

The modal amplitudes and the base displacement are obtained solving simultaneously equation (6) and equation (16) or (9). Common values of parameters for the R-FBI system are: $T_{\mathrm{b}}=4 \mathrm{~s}$ and $0.03<\mu<0.05$ and $\nu_{\mathrm{b}}=0.1$ (Mostaghel 1984; Mostaghel and Khodaverdian $1987)$.

\subsection{Electricite de France Isolator (EDF System)}

An scheme of this connection and the corresponding dynamic model is presented in Figure 8. The EDF system uses an elastomeric bearing and a friction plate in series. The equations of motion of the base in the sliding phase for a building supported on EDF isolators are given by

$$
\begin{gathered}
m_{\mathrm{b}}\left(\ddot{d}_{\mathrm{b}}+a\right)+\mu g m_{\mathrm{tot}} \operatorname{sign}\left(\dot{d}_{\mathrm{b}}-\dot{x}\right)+\boldsymbol{J}^{\mathrm{T}} \boldsymbol{M}\left[\sum_{i=1}^{q} \boldsymbol{\varphi}_{i} \ddot{\eta}_{i}(t)+\boldsymbol{J}\left(\ddot{d}_{\mathrm{b}}+a\right)\right]=0 \\
c_{\mathrm{b}} \dot{x}+k_{\mathrm{b}} x-\mu g m_{\mathrm{tot}} \operatorname{sign}\left(\dot{d}_{\mathrm{b}}-\dot{x}\right)=0
\end{gathered}
$$

Here, $k_{\mathrm{b}}$ and $c_{\mathrm{b}}$ are the equivalent stiffnes and damping coefficient of the elastomeric pad and $\mu$ is the coefficient of friction. When there is no sliding in the friction plate, the EDF base isolator behaves as a laminated rubber bearing and its motion is governed by

$$
\begin{gathered}
m_{\mathrm{b}}(\ddot{x}+a)+c_{\mathrm{b}} \dot{x}+k_{\mathrm{b}} x+\boldsymbol{J}^{\mathrm{T}} \boldsymbol{M}\left[\sum_{i=1}^{q} \boldsymbol{\varphi}_{i} \ddot{\eta}_{i}(t)+\boldsymbol{J}(\ddot{x}+a)\right]=0 \\
\dot{d}_{\mathrm{b}}-\dot{x}=0
\end{gathered}
$$


In these equations, $d_{\mathrm{b}}$ is the displacement of the base relative to the ground and $x$ is the deflection experienced by the neoprene pad.

Whenever the base sticks to the top of the elastomeric pad, equations (20) and (21) govern the motion as long as the non-sliding condition

$$
m_{\mathrm{tot}} \mu g>\left|m_{\mathrm{tot}}\left(a+\ddot{d}_{\mathrm{b}}\right)+\boldsymbol{J}^{\mathrm{T}} \boldsymbol{M} \sum_{i=1}^{q} \boldsymbol{\varphi}_{i} \ddot{\eta}_{i}(t)\right|
$$

hold. As soon as this condition fails, slip occurs and equations (18) and (19) apply. In a sliding phase, if $\dot{d}_{\mathrm{b}}=\dot{x}$, the non-sliding condition given by equation (22) must be checked in order to determine whether the sliding on the friction plate continues or the stick condition prevails. Common practical applications values for the parameters are $T_{\mathrm{b}}=1 \mathrm{~s}$ and $\mu=0.2$.

\subsection{New Zeland Isolator (NZ System)}

The NZ system is similar to the laminated rubber one but it includes a central lead core in order to reduce base relative displacement and to provide additional energy dissipation (Kelly 1986; Buckle 1985). An scheme of this connection and the corresponding dynamic model is presented in Figure 4. The force-displacement relatioship for this system can be represented using the Wen's hysteretic model (Wen 1976). Accordingly, the expression for the restoring force $f(t)$ in a hysteretic damper is

$$
f(t)=\alpha \frac{f_{\mathrm{y}}}{d_{\mathrm{y}}} d_{\mathrm{b}}(t)+(1-\alpha) f_{\mathrm{y}} z(t)
$$

where $z$ is a dimensionless hysteretic component satisfying the following non-linear first order differential equation:

$$
d_{\mathrm{y}} \dot{z}=A \dot{d}_{\mathrm{b}}-\nu|z|^{n} \dot{d}_{\mathrm{b}}-\gamma|z|^{n-1} z\left|\dot{d}_{\mathrm{b}}\right|
$$

where, $d_{\mathrm{y}}$ and $f_{\mathrm{y}}$ are the yield displacement and force of the hysteretic damper, repectively, and $A, \nu, \gamma$ and $n$ are dimensionless parameters. Parameter $n$ is an integer which controls the smoothness of the transition from elastic to plastic response and $\alpha$ is the post to preyielding stiffness ratio. The values of $f_{\mathrm{y}}=46 \mathrm{kN}, d_{\mathrm{y}}=7.7 \mathrm{~mm}, \alpha=0.157, \nu=-0.54, \gamma=1.4, A=1$ and $n=1$ are suggested so that the predicted response from the model fits the experimental results from certain lead-core laminated rubber bearings (Constantinou and Tadjbakhsh 1984). An alternative approach for the numerical simulation of the NZ isolator is to develop a finite element model taking into account the rubber, steel and lead (Ali and Abdel-Ghaffar $1995)$. is

The equation of motion of the base for a building supported on hysteretic base isolators

$$
m_{\mathrm{b}}\left(\ddot{d}_{\mathrm{b}}+a\right)+c_{\mathrm{b}} \dot{d}_{\mathrm{b}}+k_{\mathrm{b}} d_{\mathrm{b}}+\alpha \frac{f_{\mathrm{y}}}{d_{\mathrm{y}}} d_{\mathrm{b}}+(1-\alpha) f_{\mathrm{y}} z+\boldsymbol{J}^{\mathrm{T}} \boldsymbol{M}\left[\sum_{i=1}^{q} \boldsymbol{\varphi}_{i} \ddot{\eta}_{i}(t)+\boldsymbol{J}\left(\ddot{d}_{\mathrm{b}}+a\right)\right]=0
$$

where the hysteretic component $z$ is determined from the equation (24). The damping and stiffness of the base isolator are $c_{\mathrm{b}}$ and $k_{\mathrm{b}}$, respectivelly.

As noted before the system of equations governing the motion of the base mass as given by equations (24) and (25) must be solved simultaneously with equation (6) governing the time evolution of the modal amplitudes. 


\subsection{Sliding Resilient-Friction Isolator (SR-F System)}

The equations of motion of the SR-F base isolator is somewhat more involved due to the presence of two different friction coefficients. In the fully sliding phase, the equations of motion are given as

$$
\begin{gathered}
m_{\mathrm{b}}\left(\ddot{d}_{\mathrm{b}}+a\right)+\mu g m_{\mathrm{tot}} \operatorname{sign}\left(\dot{d}_{\mathrm{b}}-\dot{x}\right)+\boldsymbol{J}^{\mathrm{T}} \boldsymbol{M}\left[\sum_{i=1}^{q} \boldsymbol{\varphi}_{i} \ddot{\eta}_{i}(t)+\boldsymbol{J}\left(\ddot{d}_{\mathrm{b}}+a\right)\right]=0 \\
c_{\mathrm{b}} \dot{x}+k_{\mathrm{b}} x+\mu_{1} g m_{\mathrm{tot}} \operatorname{sign}(\dot{x})-\mu g m_{\mathrm{tot}} \operatorname{sign}\left(\dot{d}_{\mathrm{b}}-\dot{x}\right)=0
\end{gathered}
$$

where $\mu$ and $\mu_{1}$ are the coefficients of friction of the upper plate and the base isolator plates, respectively.

Whenever there is no sliding in the upper plate, but the friction plates of the base isolator are sliding, the equations of motion become

$$
\begin{gathered}
\dot{d}_{\mathrm{b}}-\dot{x}=0 \\
m_{\mathrm{b}}(\ddot{x}+a)+c_{\mathrm{b}} \dot{x}+k_{\mathrm{b}} x+\mu_{1} g m_{\mathrm{tot}} \operatorname{sign}(\dot{x})+\boldsymbol{J}^{\mathrm{T}} \boldsymbol{M}\left[\sum_{i=1}^{q} \boldsymbol{\varphi}_{i} \ddot{\eta}_{i}(t)+\boldsymbol{J}\left(\ddot{d}_{\mathrm{b}}+a\right)\right]=0
\end{gathered}
$$

In this case the behaviour of the base isolator is identical to that of the R-FBI system. When only the upper plate slides, the base isolator behaves as a pure-friction system and the equations of motion are given as

$$
\begin{gathered}
m_{\mathrm{b}}\left(\ddot{d}_{\mathrm{b}}+a\right)+\mu g m_{\mathrm{tot}} \operatorname{sign}\left(\dot{d}_{\mathrm{b}}\right)+\boldsymbol{J}^{\mathrm{T}} \boldsymbol{M}\left[\sum_{i=1}^{q} \boldsymbol{\varphi}_{i} \ddot{\eta}_{i}(t)+\boldsymbol{J}\left(\ddot{d}_{\mathrm{b}}+a\right)\right]=0 \\
\dot{x}=0
\end{gathered}
$$

If there is no sliding, the equations of motion simply become

$$
\dot{d}_{\mathrm{b}}=\dot{x}=0
$$

The non-sliding condition for the upper friction plate continues as long as

$$
m_{\mathrm{tot}} g \mu>\left|m_{\mathrm{tot}}\left(\ddot{d}_{\mathrm{b}}+a\right)+\boldsymbol{J}^{\mathrm{T}} \boldsymbol{M} \sum_{i=1}^{q} \boldsymbol{\varphi}_{i} \ddot{\eta}_{i}(t)\right|
$$

The stick condition for the friction plates in the body of the base isolator continues as long as the inequality

$$
m_{\text {tot }} g \mu_{1}>\left|m_{\text {tot }}\left(\ddot{d}_{\mathrm{b}}+a\right)+k_{\mathrm{b}} x++\boldsymbol{J}^{\mathrm{T}} \boldsymbol{M} \sum_{i=1}^{q} \boldsymbol{\varphi}_{i} \ddot{\eta}_{i}(t)\right|
$$

is satisfied.

The modal amplitudes $\eta_{i}(t)$ of the structure and the coefficients $\varphi_{i}$ are determined by the equations (6) and (5), respectively. For the SR-F base isolater to work effectively, $\mu$ must be larger than $\mu_{1}$. The values of $\mu_{1}=0.04, \mu=0.1, \nu=0.1$ and a natural period of $4 \mathrm{~s}$ for the SR-F base isolation system are used. 


\section{LINEAR THEORY OF BASE ISOLATION}

\subsection{Introduction}

It is clear that, in general, the precise analysis of structures supported on base isolation systems requires a nonlinear step by step analysis. However, for certain systems, such as the laminated rubber bearings, it is possible to linearize the nonlinear equations based on a equivalent stiffness and damping coefficients. This simplification proposed by Kelly (1991a) enables to gain insigths into the behaviour of isolated structures. For sliding isolation it is, in general, difficult to linearize the equations of motion and equivalent nonlinear single degree of freedoms systems have been proposed (Bozzo and Mahin 1990). There are also analytical solutions for the dynamic characteristics of base isolated shear buildings supported on laminated rubber bearings (Pan and Cui 1994). The aforementioned work gives exact and approximate solutions for the preliminary design of non-rigid base-isolated buildings.

An important fact which will be demonstrated in this section is that the fundamental period of rubber base isolated structures is similar to the period of the isolation devices. The original fixed base period is shifted to a much longer one. The objective is to depart the fundamental period far from the predominant period of earthquakes. For base isolated structures, the participation factors for modes larger than the first one are negligible compared to the participation of the first one. If for some reason the natural frecuency of the isolation system is close to the predominat frecuency of an earthquake, the structural response would be worse than the response of the original conventional fixed base structure. Consequently, it is important to predict accuratelly the frecuency content for the design earthquakes at the actual location of the building.

Even though the fundamental frecuency of a base isolated structure is well separated from the predominant period of an earthquake, the first mode of vibration is still excited. Therefore, damping in the base isolation system is necesary to limit maximum displacements.

The studies presented in this section for single degree of freedom structures supported on laminated rubber bearing systems are based in Kelly (1991a), Skinner et al. (1992), Skinner et al. (1993) and in Shustov (1992). The main objective is to examine the parameters that govern the behaviour of these isolated structures gaining insigths into the structural response through simple models.

\subsection{Single Degree of Freedom Models}

Figure 11 shows a single degree of freedom structure supported on neoprene pads and its corresponding dynamic model. The masses $m_{\mathrm{b}}$ and $m_{1}$ correspond to the the base and to the single degree of freedom structure, respectivelly. The stiffness $k_{\mathrm{b}}$ and the damping coeficient $c_{\mathrm{b}}$ define the mechanical properties of the isolation system. The stiffness $k_{1}$ and damping coefficient $c_{1}$ define the mechanical properties of the single degree of freedom structure.

The seismic motion is represented by the ground displacement $d(t)$, velocity $v(t)$ and acceleration $a(t)$ acting at the basement. The soil vibrations are propagated through the isolators inducing displacements in the base and structure. The displacement of mass $m_{1}$ with respect to the isolator is $d_{1}(t)$. The displacement of mass $m_{\mathrm{b}}$ with respect to the ground is $d_{\mathrm{b}}(t)$. D'Alembert dynamic equilibrium principle enables to write the equations of motion for the masses $m_{1}$ and $m_{\mathrm{b}}$

$$
\begin{gathered}
m_{1}\left[\ddot{d}_{1}(t)+\ddot{d}_{\mathrm{b}}(t)+a(t)\right]+k_{1} d_{1}(t)+c_{1} \dot{d}_{1}(t)=0 \\
m_{\mathrm{b}}\left[\ddot{d}_{\mathrm{b}}(t)+a(t)\right]+m_{1}\left[\ddot{d}_{1}(t)+\ddot{d}_{\mathrm{b}}(t)+a(t)\right]+k_{\mathrm{b}} d_{\mathrm{b}}(t)+c_{\mathrm{b}} \dot{d}_{\mathrm{b}}(t)=0
\end{gathered}
$$




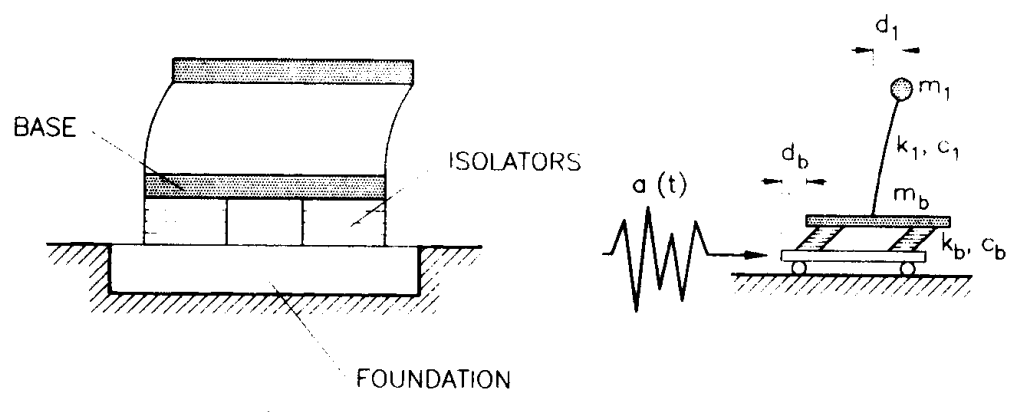

(a)

(b)

Figure 11. (a) Single degree of freedom structure with base isolation. (b) Dynamic model

In matrix notation, these equations are represented in the following compact form:

$$
\boldsymbol{M} \ddot{\boldsymbol{D}}+\boldsymbol{C} \dot{\boldsymbol{D}}+\boldsymbol{K} \boldsymbol{D}=-\boldsymbol{M} \boldsymbol{J} a(t)
$$

where

$$
\begin{aligned}
& \boldsymbol{M}=\left[\begin{array}{cc}
m_{\mathrm{b}}+m_{1} & m_{1} \\
m_{1} & m_{1}
\end{array}\right], \quad \boldsymbol{C}=\left[\begin{array}{cc}
c_{\mathrm{b}} & 0 \\
0 & c_{1}
\end{array}\right], \\
& \boldsymbol{K}=\left[\begin{array}{cc}
k_{\mathrm{b}} & 0 \\
0 & k_{1}
\end{array}\right], \quad \boldsymbol{J}=\left[\begin{array}{l}
1 \\
0
\end{array}\right], \quad \boldsymbol{D}=\left[\begin{array}{l}
d_{\mathrm{b}} \\
d_{1}
\end{array}\right]
\end{aligned}
$$

The eigenvalues and eigenvectors problem asociated to equation (37) is

$$
\left(\boldsymbol{K}-\omega^{2} \boldsymbol{M}\right) \boldsymbol{\varphi}=\mathbf{0}
$$

where $\omega$ is the frecuency of the system and $\varphi$ is the corresponding modal shape. The characteristic equation for this simple system can be expressed in the following explicit polynomial form:

$$
\omega^{4}(1-\gamma)-\omega^{2}\left(\frac{k_{\mathrm{b}}}{m_{1}+m_{\mathrm{b}}}+\frac{k_{1}}{m_{1}}\right)+\frac{k_{1}}{m_{1}} \frac{k_{\mathrm{b}}}{m_{1}+m_{\mathrm{b}}}=0
$$

where $\gamma=m_{1} /\left(m_{1}+m_{\mathrm{b}}\right)$. The solution of this equation gives the two natural frecuencies of the system. Defining the fundamental natural frecuencies of the structure $\omega_{\mathrm{s}}$ and of the isolation system $\omega_{\mathrm{b}}$ as

$$
\omega_{\mathrm{s}}=\sqrt{\frac{k_{1}}{m_{1}}}, \quad \omega_{\mathrm{b}}=\sqrt{\frac{k_{\mathrm{b}}}{m_{\mathrm{b}}+m_{1}}}
$$

allows to express equation (39) in the following form:

$$
\omega^{4}(1-\gamma)-\omega^{2}\left(\omega_{\mathrm{b}}^{2}+\omega_{\mathrm{s}}^{2}\right)+\omega_{\mathrm{b}}^{2} \omega_{\mathrm{s}}^{2}=0
$$

The solution of equation (41) is

$$
\omega^{2}=\frac{\omega_{\mathrm{b}}^{2}+\omega_{\mathrm{s}}^{2}}{2(1-\gamma)}\left[1 \pm \sqrt{1-\frac{4(1-\gamma) \varepsilon}{(1+\varepsilon)^{2}}}\right]
$$


where the coefficient $\varepsilon=\omega_{\mathrm{h}}^{2} / \omega_{\mathrm{s}}^{2}$ has been introduced.

Since the structural stiffness $k_{1}$ is much larger than the stiffness of the isolation system $k_{\mathrm{b}}$, equations (40) indicates that the parameter $\varepsilon$ is very small, about $1 \%$, according to Kelly (1991a). Consequently, considering $\varepsilon^{2} \simeq 0$ and $(1+\varepsilon)^{2} \simeq 1$ (Kelly 1993), equation (42) simplifies to

$$
\omega^{2} \simeq \frac{\omega_{\mathrm{b}}^{2}+\omega_{\mathrm{s}}^{2}}{2(1-\gamma)}[1 \pm(1-2(1-\gamma) \varepsilon)]
$$

The corresponding eigenvalues are

$$
\begin{gathered}
\omega_{1}^{2} \simeq \frac{\omega_{\mathrm{b}}^{2}+\omega_{\mathrm{s}}^{2}}{2(1-\gamma)} 2(1-\gamma) \varepsilon \simeq \omega_{\mathrm{b}}^{2}(1+\varepsilon) \simeq \omega_{\mathrm{b}}^{2} \\
\omega_{2}^{2} \simeq \frac{\omega_{\mathrm{b}}^{2}+\omega_{\mathrm{s}}^{2}}{2(1-\gamma)}(2-2 \varepsilon(1-\gamma)) \simeq \frac{\omega_{\mathrm{s}}^{2}}{1-\gamma}
\end{gathered}
$$

In these equations $\omega_{1}$ represents the modified natural frecuency of the isolation system and $\omega_{2}$ represents the modified fundamental frecuency of the structure. The eigenvectors $\boldsymbol{\varphi}_{1}$ and $\varphi_{2}$ are obtained using the frecuencies $\omega_{1}$ and $\omega_{2}$ to solve the linear system of equations (38). Following the notation

$$
\varphi_{1}^{\mathrm{T}}=\left[\begin{array}{ll}
\varphi_{1}^{\mathrm{b}} & \varphi_{1}^{\mathrm{s}}
\end{array}\right], \quad \varphi_{2}^{\mathrm{T}}=\left[\begin{array}{ll}
\varphi_{2}^{\mathrm{b}} & \varphi_{2}^{\mathrm{s}}
\end{array}\right]
$$

where $\mathrm{s}$ corresponds to the structure and b corresponds to the base and using equation (38) the following two equations are written:

$$
\begin{aligned}
& {\left[k_{\mathrm{b}}-\omega_{1}^{2}\left(m_{\mathrm{b}}+m_{1}\right)\right] \varphi_{1}^{\mathrm{b}}-\omega_{1}^{2} m_{1} \varphi_{1}^{\mathrm{s}}=0} \\
& {\left[k_{\mathrm{b}}-\omega_{2}^{2}\left(m_{\mathrm{b}}+m_{1}\right)\right] \varphi_{2}^{\mathrm{b}}-\omega_{2}^{2} m_{1} \varphi_{2}^{\mathrm{s}}=0}
\end{aligned}
$$

The eigenvector $\varphi_{1}$ is normalized as $\varphi_{1}^{\mathrm{b}}=1$. Therefore

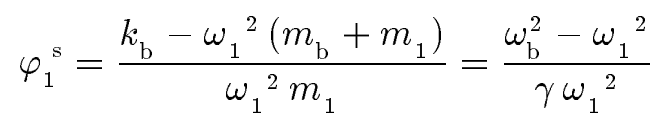

and, considering equation (44), the fundamental frecuency is aproximated to the frecuency of the isolation device as $\omega_{1}^{2} \simeq \omega_{\mathrm{b}}^{2}$. According to these simplifications

$$
\varphi_{1}^{\mathrm{s}} \simeq \frac{\omega_{\mathrm{b}}^{2}-\omega_{\mathrm{b}}^{2}(1+\varepsilon)}{\gamma \omega_{\mathrm{b}}^{2}(1+\varepsilon)}=\frac{-\varepsilon}{\gamma(1+\varepsilon)} \simeq \frac{-\varepsilon}{\gamma}
$$

Normalizing the second mode shape as $\varphi_{2}^{\mathrm{b}}=1$, enables to write

$$
\varphi_{2}^{\mathrm{s}}=\frac{k_{\mathrm{b}}-\omega_{2}^{2}\left(m_{\mathrm{b}}+m_{1}\right)}{\omega_{2}^{2} m_{1}}=\frac{\omega_{\mathrm{b}}^{2}-\omega_{2}^{2}}{\gamma \omega_{2}^{2}}
$$

Taking into account equation (45), an approximate value for the second natural frecuency of the system is $\omega_{2}{ }^{2} \simeq \omega_{\mathrm{s}}^{2} /(1-\gamma)$, which permits to write $\varphi_{2}^{\mathrm{s}}$ as

$$
\varphi_{2}^{\mathrm{s}} \simeq \frac{(1-\gamma) \omega_{\mathrm{b}}^{2}-\omega_{\mathrm{s}}^{2}}{\gamma \omega_{\mathrm{s}}^{2}}=\frac{\varepsilon(1-\gamma)-1}{\gamma} \simeq \frac{-1}{\gamma}
$$


Therefore, the eigenvectors have the following approximate expresions:

$$
\begin{aligned}
& \boldsymbol{\varphi}_{1}^{\mathrm{T}}=\left[\begin{array}{ll}
1 & -\varepsilon / \gamma
\end{array}\right] \\
& \boldsymbol{\varphi}_{2}^{\mathrm{T}}=\left[\begin{array}{ll}
1 & -1 / \gamma
\end{array}\right]
\end{aligned}
$$

The vectors $\varphi_{1}$ and $\varphi_{2}$ form a complete base and they are used to uncoupled the equations of motion (37), writting

$$
\boldsymbol{D}(t)=\left[\begin{array}{l}
d_{\mathrm{b}}(t) \\
d_{1}(t)
\end{array}\right]=\eta_{1}(t) \boldsymbol{\varphi}_{1}+\eta_{2}(t) \boldsymbol{\varphi}_{2}
$$

where $\eta_{1}(t)$ and $\eta_{2}(t)$ are the unknown time functions. Taking into account the components $x_{\mathrm{b}}(t)$ and $x_{1}(t)$ individually and considering equations (51) and (52), it is obtained

$$
\begin{gathered}
x_{\mathrm{b}}(t)=\eta_{1}(t) \boldsymbol{\varphi}_{1}^{\mathrm{b}}+\eta_{2}(t) \boldsymbol{\varphi}_{2}^{\mathrm{b}}=\eta_{1}(t)+\eta_{2}(t) \\
x_{1}(t)=\eta_{1}(t) \varphi_{1}^{\mathrm{s}}+\eta_{2}(t) \varphi_{2}^{\mathrm{s}}=\frac{-\varepsilon}{\gamma} \eta_{1}(t)-\frac{\eta_{2}(t)}{\gamma}
\end{gathered}
$$

Substituting equation (53) into equation (37) and considering the orthogonality properties of the modal matrix $\boldsymbol{\Phi}=\left[\begin{array}{ll}\boldsymbol{\varphi}_{1} & \boldsymbol{\varphi}_{2}\end{array}\right]$ with respect to the mass $\boldsymbol{M}$, stiffness $\boldsymbol{K}$ and damping matrix $C$, it is obtained

$$
\begin{aligned}
& \ddot{\eta}_{1}(t)+2 \omega_{1} \nu_{1} \dot{\eta}_{1}(t)+\omega_{1}^{2} \eta_{1}(t)=-Q_{1} a(t) \\
& \ddot{\eta}_{2}(t)+2 \omega_{2} \nu_{2} \dot{\eta}_{2}(t)+\omega_{2}^{2} \eta_{2}(t)=-Q_{2} a(t)
\end{aligned}
$$

where the following notations are used:

$$
\frac{\varphi_{i}^{\mathrm{T}} \boldsymbol{C} \boldsymbol{\varphi}_{i}}{\boldsymbol{\varphi}_{i}^{\mathrm{T}} \boldsymbol{M} \boldsymbol{\varphi}_{i}}=2 \omega_{i} \nu_{i}, \quad \frac{\boldsymbol{\varphi}_{i}^{\mathrm{T}} \boldsymbol{K} \boldsymbol{\varphi}_{i}}{\varphi_{i}^{\mathrm{T}} \boldsymbol{M} \boldsymbol{\varphi}_{i}}=\omega_{i}^{2}, \quad \frac{\varphi_{i}^{\mathrm{T}} \boldsymbol{M J}}{\boldsymbol{\varphi}_{i}^{\mathrm{T}} \boldsymbol{M} \boldsymbol{\varphi}_{i}}=Q_{i}, \quad i=1,2
$$

where $\nu_{1}$ and $\nu_{2}$ are the damping ratios corresponding to the two modes.

Equations (44) and (51), and the aforementioned definitions for $\boldsymbol{M}$ and $\boldsymbol{C}$, enable to write the following equations:

$$
\begin{gathered}
\boldsymbol{\varphi}_{1}^{\mathrm{T}} \boldsymbol{C} \boldsymbol{\varphi}_{1}=c_{\mathrm{b}}+\frac{c_{1} \varepsilon^{2}}{\gamma^{2}} \\
\boldsymbol{\varphi}_{1}^{\mathrm{T}} \boldsymbol{M} \boldsymbol{\varphi}_{1}=m_{\mathrm{b}}+m_{1}-\frac{2 \varepsilon m_{1}}{\gamma}+\frac{\varepsilon^{2} m_{1}}{\gamma^{2}}
\end{gathered}
$$

Using equation (58) and neglecting the $\varepsilon^{2}$ terms, the damping ratio $\nu_{1}$ is

$$
\nu_{1} \simeq \frac{c_{\mathrm{b}}}{2 \omega_{1}\left(m_{\mathrm{b}}+m_{1}\right)} \frac{1}{1-2 \varepsilon}
$$

Applying Taylor'series to the former equation the coefficient $\nu_{1}$ simplifies to

$$
\nu_{1} \simeq \frac{c_{\mathrm{b}}}{2 \omega_{1}\left(m_{\mathrm{b}}+m_{1}\right)}\left(1+2 \varepsilon+4 \varepsilon^{2}+\ldots\right) \simeq \frac{c_{\mathrm{b}}}{2 \omega_{1}\left(m_{\mathrm{b}}+m_{1}\right)}
$$


Defining

$$
\nu_{\mathrm{b}}=\frac{c_{\mathrm{b}}}{2 \omega_{\mathrm{b}}\left(m_{\mathrm{b}}+m_{1}\right)}
$$

as damping ratio for the isolators and using again $\omega_{1} \simeq \omega_{\mathrm{b}}$, it is concluded that $\nu_{1} \simeq \nu_{\mathrm{b}}$.

The definitions for $\boldsymbol{M}$ and $\boldsymbol{J}$ along with expresion (51) for $\boldsymbol{\varphi}_{1}^{\mathrm{T}}$ allow to evaluate $\boldsymbol{\varphi}_{1}^{\mathrm{T}} \boldsymbol{M} \boldsymbol{J}$

$$
\boldsymbol{\varphi}_{1}^{\mathrm{T}} \boldsymbol{M} \boldsymbol{J}=m_{\mathrm{b}}+m_{1}-\frac{m_{1} \varepsilon}{\gamma}
$$

From result (60) and equation (64), the definition (58) for the coefficient $Q_{1}$ is written as

$$
Q_{1}=\frac{m_{\mathrm{b}}+m_{1}-\varepsilon m_{1} / \gamma}{m_{\mathrm{b}}+m_{1}-2 \varepsilon m_{1} / \gamma+\varepsilon^{2} m_{1} / \gamma^{2}}=\frac{1-\varepsilon}{1-2 \varepsilon+\varepsilon^{2} / \gamma} \simeq 1
$$

The terms $\boldsymbol{\varphi}_{2}^{\mathrm{T}} \boldsymbol{C} \boldsymbol{\varphi}_{2}$ and $\boldsymbol{\varphi}_{2}^{\mathrm{T}} \boldsymbol{M} \boldsymbol{\varphi}_{2}$ are rewritten using equations (45) and (52), as well as the definitions for $C$ and $\boldsymbol{M}$

$$
\begin{gathered}
\boldsymbol{\varphi}_{2}^{\mathrm{T}} \boldsymbol{C} \boldsymbol{\varphi}_{2}=c_{\mathrm{b}}+\frac{c_{1}}{\gamma^{2}} \\
\boldsymbol{\varphi}_{2}^{\mathrm{T}} \boldsymbol{M} \boldsymbol{\varphi}_{2}=m_{\mathrm{b}}+m_{1}-\frac{2 m_{1}}{\gamma}+\frac{m_{1}}{\gamma^{2}}
\end{gathered}
$$

The second equation (58) enables to express $\nu_{2}$ as

$$
\nu_{2}=\frac{1}{2 \omega_{2}} \frac{c_{\mathrm{b}}+c_{1} / \gamma^{2}}{m_{\mathrm{b}}+m_{1}-2 m_{1} / \gamma+m_{1} / \gamma^{2}}=\frac{1}{2 \omega_{2} m_{1}} \frac{c_{\mathrm{b}} \gamma^{2}+c_{1}}{1-\gamma}
$$

Considering the approximate value for $\omega_{2}^{2}$ given by equation (45), it is obtained

$$
\nu_{2} \simeq \frac{1}{2 \omega_{\mathrm{s}} m_{1}} \frac{c_{\mathrm{b}} \gamma^{2}+c_{1}}{\sqrt{1-\gamma}}
$$

The definition for the damping ratio $\nu_{\mathrm{s}}$ for the structure

$$
\nu_{\mathrm{s}}=\frac{c_{1}}{2 \omega_{\mathrm{s}} m_{1}}
$$

is introduced, and equation (69) is rewritten as (Kelly 1993)

$$
\nu_{2} \simeq \frac{1}{\sqrt{1-\gamma}}\left[\nu_{\mathrm{s}}+\frac{c_{\mathrm{b}} \gamma^{2}}{2 \omega_{\mathrm{s}} m_{1}}\right]=\frac{1}{\sqrt{1-\gamma}}\left[\nu_{\mathrm{s}}+\gamma \nu_{\mathrm{b}} \sqrt{\varepsilon}\right]
$$

This results shows that the structural damping is increased by the isolator damping afected by a factor $\gamma \sqrt{\varepsilon}$. The product $\gamma \nu_{\mathrm{b}} \sqrt{\varepsilon}$ may contribute significantly to the term $\nu_{\mathrm{s}}$. Consequently, a high damping coefficient for the isolators contributes significantly to reduce the response in the second mode of vibration. This fact is positive because a significant response in the second mode would considerably reduce the advantages of seismic isolation.

$Q_{2}$ it is obtained using the expressions $\varphi_{2}^{\mathrm{T}} \boldsymbol{M} \boldsymbol{J}$ and $\boldsymbol{\varphi}_{2}^{\mathrm{T}} \boldsymbol{M} \boldsymbol{\varphi}_{2}$

$$
\boldsymbol{\varphi}_{2}^{\mathrm{T}} \boldsymbol{M} \boldsymbol{J}=m_{\mathrm{b}}+m_{1}+m_{1} \frac{\varepsilon(1-\gamma)-1}{\gamma}
$$




$$
\boldsymbol{\varphi}_{2}^{\mathrm{T}} \boldsymbol{M} \boldsymbol{\varphi}_{2}=m_{\mathrm{b}}+m_{1}+2 m_{1} \frac{\varepsilon(1-\gamma)-1}{\gamma}+m_{1}\left(\frac{\varepsilon(1-\gamma)-1}{\gamma}\right)^{2}
$$

where, in this case, expression (50) has been used to write $\varphi_{2}$. Equation (72) is expanded to

$$
\boldsymbol{\varphi}_{2}^{\mathrm{T}} \boldsymbol{M} \boldsymbol{J}=\left(m_{\mathrm{b}}+m_{1}\right)(1-\gamma) \varepsilon
$$

Neglecting $\varepsilon$ terms, equation (73) is simplified as

$$
\boldsymbol{\varphi}_{2}^{\mathrm{T}} \boldsymbol{M} \boldsymbol{\varphi}_{2}=\frac{\left(m_{\mathrm{b}}+m_{1}\right)^{2}}{m_{1}}(1-\gamma)
$$

The expresion for the mode participation factor $Q_{2}$ is obtained substituting equations (74) and (75) in equation (58)

$$
Q_{2} \simeq \gamma \varepsilon
$$

The results enable to make some general observations about the behaviour of base isolated structures. If the fundamental frecuency of an earthquake is close to the natural fix base frecuency of a building, the base isolation system should have a frecuency far from them. A protected single degree of freedom structure has two natural frecuencies $\omega_{1}$ and $\omega_{2}$ while the similar but unprotected structure has one frecuency $\omega_{\mathrm{s}}$. Equation (44) shows that the frecuency $\omega_{1}$ is similar to $\omega_{\mathrm{b}}$. In order to avoid resonance between the first mode frecuency and the predominant frecuency of an earthquake, it is convenient that $\omega_{1}$ be smaller than $\omega_{s}$. Furthermore as equations (51) show, the displacements in the first mode are concentrated at the isolation raft, while the structural interstory drift is very small, the system behaving almost as a rigid body (Bozzo and Mahin 1990; Kircher and Lashkari 1989).

The second natural frecuency, $\omega_{2}$, is larger than $\omega_{s}$, and may be enough in order to avoid resonance in the second mode. Equation (52) indicates the potential danger of a building vibrating in the second mode since interstory drifts are increased compared to the first mode. However, equation (76) shows that the participation factor for the second mode is small and close to $\varepsilon$ which is about 0.01. The coefficient $\gamma$ is always smaller than one and therefore it reduces even further the participation factor. As a result, the acceleration $a(t)$ is considerably reduced in equation (57). Consequently, even for a second mode resonance condition, the response $\eta_{2}(t)$ would be small. A general conclusion applicable to rubber isolation systems is that the response is minimized not by energy dissipation but by changing the dynamics of the original system.

There are, however, earthquakes whose predominant frecuency may be low and close to the frecuency $\omega_{1}$. Such isolated systems respond worse than non isolated buildings. In this case the response is limited by the damping $\nu_{\mathrm{b}}$ which for rubber systems varies between $5 \%$ and $30 \%$ of the critical one (Derham 1986; Tajirian and Kelly 1987). A commonly used value is $10 \%$.

It is clear from previous considerations the necesity of proper seismological studies in order to determine the range of predominant earthquake periods expected at a given location. A sound base isolation design depends greatly on such studies.

Table 1 summarizes the order of magnitude on the response for isolated structures subjected to the armonic motion $a(t)=d_{\max } \sin (\theta t)$. The amplification coefficients $A_{\mathrm{s}}$ and $A_{\mathrm{b}}$ are defined as

$$
A_{\mathrm{s}}=\frac{\left|d_{1}(t)\right|_{\max }}{d_{\max }}
$$




$$
A_{\mathrm{b}}=\frac{\left|d_{\mathrm{b}}(t)\right|_{\max }}{d_{\max }}
$$

where $d_{\max }$ is the maximum ground displacement. The amplification coefficient $A$ corresponds to a linear elastic unprotected single degree of freedom structure with a similar fundamental period. The excitation frecuency is $\theta$.

The two cases in which the order of magnitude for the amplification factor is $1 / \varepsilon$ confirm the aforementioned danger of an excitation frecuency close to the frecuency of the isolation devices. Some authors (Lin et al. 1989) attribute the efectiveness of base isolation to its energy dissipation capacities, not relying on its period shift. In general, sliding isolation devices reduce dynamic forces though energy dissipation and not by their period shift (Zayas et al. 1989). Certainly, for rubber base isolation, if the excitation frecuency is close to the fundamental one of the isolated building, the maximum response is limited by the isolator damping. The proximity of both frecuencies may be caused by uncertainties in the definition of the input motion. Besides an earthquake is composed by different frecuencies which vary along the wave propagation. There are some strong earthquake records measured at close epicentral distances, such as the Pacoima Dam one during the San Fernando Earthquake in 1971, that indicate clearly the presence of long pulses atributed to the epicentral proximity. Those long pulses may also contribute negatively to the response of isolated buildings concentrating large displacements at the base raft.

\begin{tabular}{|c|c|c|c|}
\hline$\theta$ & $A$ & $A_{\mathrm{s}}$ & $A_{\mathrm{b}}$ \\
\hline$\omega_{1}$ & $\varepsilon$ & 1 & $1 / \varepsilon$ \\
$\omega_{2}$ & 1 & 1 & 1 \\
$\omega_{\mathrm{s}}$ & $1 / \varepsilon$ & $\varepsilon$ & 1 \\
\hline
\end{tabular}

Table 1. Order of magnitude for the structural response

From Table 1, the most favorable situation corresponds to an armonic motion close to the building frecuency $\omega_{\mathrm{s}}$. In this case, the amplification factor $A_{\mathrm{s}}$ for a rubber isolated building is $\varepsilon$ which is a much lower factor than the corresponding one for a fix base structure $1 / \varepsilon$. The amplification factor for the base is $A_{\mathrm{b}}$ which in this case has an order of magnitude 1. Furthermore, the amplification factors $A_{\mathrm{b}}$ and $A_{\mathrm{s}}$ corresponding to the second mode also have an order of magnitude 1.

It is difficult to perform a comparative study about the reponse of isolated structures, since there is not a unique criteria for such evaluation. For example, Hadjian and Tseng (1986) suggest eleven different considerations. The most accepted ones are to limit the maximum base displacements, to limit the maximum roof accelerations and to limit the maximum roof drift. The maximum base displacement is important since it governs the design of the service lines such as pipes and wires connecting the ground and the building. If the maximum base displacement exceeds the design value the whole advantages of isolation are missed. An eventual impact between the isolation base and the surrounding foundation may cause high frecuencies and dynamic amplifications. Furthermore, some of the few buildings dynamically isolated and already subjected to strong earthquakes have experience such problems. The roof acceleration is an important parameter which governs the damage to the building equipment. The roof drift is a measure of the nonstructural damage that may be caused by an earthquake. 


\subsection{Multy Degree of Freedom Structures}

The extension of the linear base isolation theory presented in section (4.2) has been developed by Kelly (1993). The analytical model is similar to the one for a single degree of freedom structure. In matrix notation, the equation of motion in this case is

$$
\boldsymbol{M} \ddot{\boldsymbol{D}}+\boldsymbol{C} \dot{\boldsymbol{D}}+\boldsymbol{K} \boldsymbol{D}=-\boldsymbol{M} \boldsymbol{J} a(t)
$$

where

$$
\begin{gathered}
\boldsymbol{M}=\left[\begin{array}{cc}
m_{\mathrm{b}}+m_{\mathrm{T}} & \boldsymbol{J}^{\mathrm{T}} \boldsymbol{M}_{\mathrm{s}} \\
\boldsymbol{M}_{\mathrm{s}} \boldsymbol{J} & \boldsymbol{M}_{\mathrm{s}}
\end{array}\right], \quad \boldsymbol{C}=\left[\begin{array}{cc}
c_{\mathrm{b}} & 0 \\
\mathbf{0} & \boldsymbol{C}_{\mathrm{s}}
\end{array}\right] \\
\boldsymbol{K}=\left[\begin{array}{cc}
k_{\mathrm{b}} & 0 \\
\mathbf{0} & \boldsymbol{K}_{\mathrm{s}}
\end{array}\right], \quad \boldsymbol{J}=\left[\begin{array}{l}
1 \\
\mathbf{0}
\end{array}\right], \quad \boldsymbol{D}=\left[\begin{array}{l}
d_{\mathrm{b}} \\
\boldsymbol{D}_{\mathrm{s}}
\end{array}\right]
\end{gathered}
$$

$\boldsymbol{K}_{\mathrm{s}}$ is the structural lateral stiffness matrix, $\boldsymbol{C}_{\mathrm{s}}$ is the structural damping matrix, $m_{\mathrm{T}}$ is the total structural mass $m_{\mathrm{T}}=\sum_{i=1}^{N} m_{i}$ and $m_{i}$ is the story mass.

The eigenvalues and eigenvectors problem asociated to equation (79) is

$$
\left(\boldsymbol{K}-\omega^{2} \boldsymbol{M}\right) \boldsymbol{\varphi}=\mathbf{0}
$$

assuming that $\varphi_{i} C \varphi_{j}=0$, if $i \neq j$.

The mode shapes and natural frecuencies can be obtained directly from these equations using any standard procedure. Kelly (1993) indicates, however, that such alternative may conduce to numerical errors caused by a bad conditioned matrix since the diagonal element is two orders of magnitude smaller than the others. Therefore, he proposes an iterative procedure based on the fix base eigenvalues and eigenvectors. Numerical results indicate that the high frecuencies are not affected by the isolators and they are close to the original fix base ones. Clearly, the low frecuencies are strongly shifted by the isolators.

\section{NONLINEAR THEORY OF BASE ISOLATION}

\subsection{Introduction}

A numerical simulation of the seismic response of structures equipped with base isolators requires efficient algorithms capable of performing nonlinear step by step analyses (Nagarajaiah et al. 1991). Different numerical schemes for solving the equations of motion have been proposed. The most often used numerical procedures are monolithic step-by-step integration schemes. These schemes lead to algebraic systems of equations involving both the degrees of freedom corresponding to the structure and the foundation. This approach, however, is not efficient since it does not take into account that the nonlinearities introduced by the isolators are localized just at certain predefined locations. Therefore, static condensation schemes have been proposed, in order to reduce the size of the nonlinear problem (Leger et al. 1986). Besides static condensation, there is the possibility of coupling the two sets of unknowns interatively, rather than by solving the full algebraic system. These iterative methods, when combined with the proper linearization of the nonlinear terms, yield block iterative schemes (Barbat et al. 1996). The application of static condensation and of iterative schemes in computing the seismic response of building structures with base isolation is considered, being this a problem of two systems coupled across their boundary conditions. 


\subsection{Monolithic Step-by-step Integration Schemes}

Consider the equation of motion

$$
M \ddot{D}+C \dot{D}+f(D)=F
$$

which is similar to equation (79) but the vector $\boldsymbol{f}(\boldsymbol{D})$ represents the nonlinear forces.

The monolithic step-by-step integration schemes solve the equivalent nonlinear static problem at each step, considering the complete system. These procedures do not partition the degrees of freedom into those corresponding to the linear and nonlinear regions. At each step, the solution is obtained using a tangent stiffness matrix or using a pseudo-force approach. The evaluation and decomposition of the tangent stiffness matrix at each time step is a costly procedure and consequently this approach is not convenient (Leger et al. 1986). An alternative is to evaluate equivalent pseudo static forces at each time step. The equation of motion becomes

$$
\boldsymbol{M} \ddot{\boldsymbol{D}}+\boldsymbol{C} \dot{\boldsymbol{D}}+\boldsymbol{K}_{\mathrm{o}} \boldsymbol{D}=\boldsymbol{F}-\boldsymbol{F}_{\mathrm{N}}
$$

where the vector $\boldsymbol{f}(\boldsymbol{D})$ is linearized in the following form:

$$
\boldsymbol{f}(\boldsymbol{D})=\boldsymbol{K}_{\mathrm{o}} \boldsymbol{D}+\boldsymbol{F}_{\mathrm{N}}
$$

The stiffness matrix $\boldsymbol{K}_{\mathrm{o}}$ is thus linear and the pseudo load vector $\boldsymbol{F}_{\mathrm{N}}$ is displacementdependent. The matrix $\boldsymbol{K}_{\mathrm{o}}$ can be the initial tangent stiffness.

The main advantage of this alternative is that the original stiffness matrix is decomposed once at the begining of the time integration process. At each step the nonlinear problem is restricted to the evaluation of the pseudo forces. If these forces are limited to a small number of components, the approach is efficient since the computations are at the element level.

\subsection{Static Condensation Schemes}

The monolithic integration schemes presented previously do not take into consideration that base isolation devices are located just at certain predefined locations. Besides, the number of degrees of freedom asociated to the isolators is ussually very small compared to the total number of degrees of freedom. A more rational approach based on substructuring techniques has been proposed by Leger et al. (1986). This approach was initially used for the dynamic analysis of structures having localized nonlinearities. One alternative is to partition the equations of motion as

$$
\boldsymbol{M}=\left[\begin{array}{ll}
\boldsymbol{M}_{11} & \boldsymbol{M}_{12} \\
\boldsymbol{M}_{21} & \boldsymbol{M}_{22}
\end{array}\right], \quad \boldsymbol{C}=\left[\begin{array}{ll}
\boldsymbol{C}_{11} & \boldsymbol{C}_{12} \\
\boldsymbol{C}_{21} & \boldsymbol{C}_{22}
\end{array}\right], \quad \boldsymbol{K}=\left[\begin{array}{ll}
\boldsymbol{K}_{11} & \boldsymbol{K}_{12} \\
\boldsymbol{K}_{21} & \boldsymbol{K}_{22}
\end{array}\right]
$$

and define the following transformation matrix:

$$
\boldsymbol{T}=\left[\begin{array}{cc}
\boldsymbol{\Phi}_{11} & -\boldsymbol{K}_{11}^{-1} \boldsymbol{K}_{12} \\
\mathbf{0} & \boldsymbol{I}
\end{array}\right], \quad \eta=\boldsymbol{T} \boldsymbol{D}
$$

where $\Phi_{11}$ is the fix base modal matrix corresponding to the first $q$ modes of vibration with dimensions $(n \times q)$ for the nonisolated structure. The degrees of freedom 1 and 2 correspond to the linear and nonlinear regions, respectively. Using this transformation matrix 
the equation of motion is modified to

$$
\boldsymbol{M}^{*} \ddot{\eta}+\boldsymbol{C}^{*} \dot{\eta}+\boldsymbol{K}_{\mathrm{N}}^{*} \eta=\boldsymbol{F}^{*}
$$

where

$$
\boldsymbol{M}^{*}=\boldsymbol{T}^{\mathrm{T}} \boldsymbol{M} \boldsymbol{T}, \quad \boldsymbol{C}^{*}=\boldsymbol{T}^{\mathrm{T}} \boldsymbol{C} \boldsymbol{T}, \quad \boldsymbol{K}_{\mathrm{N}}^{*}=\boldsymbol{T}^{\mathrm{T}} \boldsymbol{K} \boldsymbol{T}, \quad \boldsymbol{F}^{*}=\boldsymbol{T}^{\mathrm{T}} \boldsymbol{F}
$$

The transformation uncouples the equations of motion and the mass, damping and stiffness matrix are written as follows:

$$
\begin{gathered}
\boldsymbol{M}^{*}=\left[\begin{array}{cc}
\boldsymbol{\Phi}_{11} \boldsymbol{M}_{11} \boldsymbol{\Phi}_{11} & \boldsymbol{\Phi}_{11} \boldsymbol{M}_{12}-\boldsymbol{\Phi}_{11} \boldsymbol{M}_{11} \boldsymbol{K}_{11}^{-1} \boldsymbol{K}_{12} \\
\boldsymbol{M}_{21} \boldsymbol{\Phi}_{11}-\boldsymbol{K}_{21} \boldsymbol{K}_{11}^{-1} \boldsymbol{M}_{11} \boldsymbol{\Phi}_{11} & \boldsymbol{A}
\end{array}\right] \\
\boldsymbol{C}^{*}=\left[\begin{array}{cc}
\boldsymbol{\Phi}_{11} \boldsymbol{C}_{11} \boldsymbol{\Phi}_{11} & \boldsymbol{\Phi}_{11} \boldsymbol{C}_{12}-\boldsymbol{\Phi}_{11} \boldsymbol{C}_{11} \boldsymbol{K}_{11}^{-1} \boldsymbol{K}_{12} \\
\boldsymbol{C}_{21} \boldsymbol{\Phi}_{11}-\boldsymbol{K}_{21} \boldsymbol{K}_{11}^{-1} \boldsymbol{C}_{11} \boldsymbol{\Phi}_{11} & \boldsymbol{B}
\end{array}\right] \\
\boldsymbol{K}^{*}=\left[\begin{array}{cc}
\boldsymbol{\Phi}_{11} \boldsymbol{K}_{11} \boldsymbol{\Phi}_{11} & \mathbf{0} \\
\mathbf{0} & \boldsymbol{K}_{22}-\boldsymbol{K}_{21} \boldsymbol{K}^{-1}{ }_{11} \boldsymbol{K}_{12}
\end{array}\right]
\end{gathered}
$$

where

$$
\begin{gathered}
\boldsymbol{A}=\boldsymbol{K}_{21} \boldsymbol{K}_{11}^{-1} \boldsymbol{M}_{11} \boldsymbol{K}_{11}^{-1} \boldsymbol{K}_{12}-\boldsymbol{K}_{21} \boldsymbol{K}_{11}^{-1} \boldsymbol{M}_{12}-\boldsymbol{M}_{21} \boldsymbol{K}_{11}^{-1} \boldsymbol{K}_{12} \\
\boldsymbol{B}=\boldsymbol{K}_{21} \boldsymbol{K}_{11}{ }^{-1} \boldsymbol{C}_{11} \boldsymbol{K}_{11}^{-1} \boldsymbol{K}_{12}-\boldsymbol{K}_{21} \boldsymbol{K}_{11}^{-1} \boldsymbol{C}_{12}-\boldsymbol{C}_{21} \boldsymbol{K}_{11}^{-1} \boldsymbol{K}_{12}
\end{gathered}
$$

The vector basis $\boldsymbol{\Phi}_{11}$ for the transformation can be the standard mode shapes or the Ritz vectors presented in reference (Leger et al. 1986). The advantage is that the vector basis needs to include just a few modes. Using mode shapes or Ritz vectors the advantage of this approach is to reduce considerably the size of the problem. The eigenvectors or the Ritz vectors are calculated once at the begining of the integration. At each step the nonlinear problem is limited by the degrees of freedom for the isolator devices.

Usually, in rubber base isolation there is an additional story above the isolators. This story is rigid on its own plane and, consequently, the number of degrees of freedom to fully represent the nonlinear problem is just 3. For sliding base isolation, this is not necessarily the case and the aforementioned San Francisco Court of Appealings is being retroffited using a single isolator below each column without a rigid floor. Consequently, the number of degrees of freedom, in this case, is in general, $6 \times n_{c}$ where $n_{c}$ is the number of isolators. This number is still small compared to the total number of degrees of freedom.

\subsection{Block Iterative Schemes}

A monolithic algorithm requires a certain discretization procedure for the equations of motion and solves them in a single iterative loop that considers their linearization and coupling ( $\mathrm{Su}$ et al. 1989). The structure-base system is difficult to analyse and any numerical procedure requires the use of very small time increments. They all have the disadvantage of requiring a large number of iterations, as their convergence process is very slow. An alternative is the block iteration which reduces the number of iterations and improve convergence (Codina 1992). An efficiency study is made in Barbat et al. (1996), by comparing the block iteration scheme to the monolithic scheme, which treats non-linearity as an iterative actualization of the isolation force $f$. 
The Newmark discretization for the velocity and the acceleration for a nonlinear system is (Barbat and Canet 1994)

$$
\begin{gathered}
\ddot{\boldsymbol{D}}_{k+1}=\frac{1}{\beta \triangle t^{2}}\left[\boldsymbol{D}_{k+1}-D_{k}-\dot{\boldsymbol{D}}_{k} \triangle t\right]-\left(\frac{1}{2 \beta}-1\right) \ddot{\boldsymbol{D}}_{k} \\
\dot{\boldsymbol{D}}_{k+1}=\frac{\gamma}{\beta \triangle t}\left(\boldsymbol{D}_{k+1}-\boldsymbol{D}_{k}\right)+\left(1-\frac{\gamma}{\beta}\right) \dot{\boldsymbol{D}}_{k}+\left(1-\frac{\gamma}{2 \beta}\right) \triangle t \ddot{\boldsymbol{D}}_{k}
\end{gathered}
$$

In equations $(89)-(90)$, the subscript $k$ refers to the time step considered.

\section{General theory}

The equations that describe a generic coupled problem may be reduced by the application of a discretization procedure to a non-linear algebraic system with the form (Codina 1992)

$$
\left[\begin{array}{ll}
\boldsymbol{A}_{11} & \boldsymbol{A}_{12} \\
\boldsymbol{A}_{21} & \boldsymbol{A}_{22}(\boldsymbol{y})
\end{array}\right]\left[\begin{array}{l}
\boldsymbol{x} \\
\boldsymbol{y}
\end{array}\right]=\left[\begin{array}{l}
\boldsymbol{q}_{1} \\
\boldsymbol{q}_{2}
\end{array}\right]
$$

where $\boldsymbol{x}$ and $\boldsymbol{y}$ are the vectors to be determined, $\boldsymbol{q}_{1}$ and $\boldsymbol{q}_{2}$ are the force vectors and $\boldsymbol{A}_{i j}, i, j=1,2$ are matrices with $\boldsymbol{A}_{22}$ depending on $\boldsymbol{y}$. The equations of system (91) are coupled linearly. The matrix $\boldsymbol{A}_{22}$ is linearized in the following way:

$$
\boldsymbol{A}_{22}\left(\boldsymbol{y}^{(i)}\right) \boldsymbol{y}^{(i)} \approx \boldsymbol{A}_{22}^{\mathrm{L}} y^{(i)}+\boldsymbol{\psi}\left(\boldsymbol{y}^{(i-1)}\right)
$$

where $\boldsymbol{A}_{22}^{\mathrm{L}}$ is a linearized form of $\boldsymbol{A}_{22}$. Starting from equation (91) the following monolithic form can be obtained

$$
\left[\begin{array}{ll}
A_{11} & A_{12} \\
A_{21} & A_{22}^{\mathrm{L}}
\end{array}\right]\left[\begin{array}{l}
\boldsymbol{x}^{(i)} \\
\boldsymbol{y}^{(i)}
\end{array}\right]=\left[\begin{array}{c}
\boldsymbol{q}_{1} \\
\boldsymbol{q}_{2}-\boldsymbol{\psi}\left(y^{(i-1)}\right)
\end{array}\right]
$$

Using equation (93) the coupling equations for block iteration can be written using blockJacobi:

$$
\begin{gathered}
\boldsymbol{A}_{11} \boldsymbol{x}^{(i)}=\boldsymbol{q}_{1}-\boldsymbol{A}_{12} \boldsymbol{y}^{(i-1)} \\
\boldsymbol{A}_{22}^{\mathrm{L}} \boldsymbol{y}^{(i)}=\boldsymbol{q}_{2}-\boldsymbol{\psi}\left(\boldsymbol{y}^{(i-1)}\right)-\boldsymbol{A}_{21} \boldsymbol{x}^{(i-1)}
\end{gathered}
$$

This represents a first approach for implementing the block iteration procedure. Equation (94) is solved first to give a value for $\boldsymbol{x}^{(i)}$, and this is then used to solve equation (95) to give the vector $\boldsymbol{y}^{(i)}$.

Case of the uncoupled structure

The uncoupled equations of motion for the structure and the isolator (6) and (7) may be expressed in the following compact form

$$
\begin{gathered}
\ddot{\boldsymbol{\eta}}+2 \boldsymbol{\nu} \boldsymbol{\Omega} \dot{\boldsymbol{\eta}}+\boldsymbol{\Omega}^{2} \boldsymbol{\eta}+\frac{\boldsymbol{\Phi}^{\mathrm{T}} \boldsymbol{M} \boldsymbol{J}}{\boldsymbol{\Phi}^{\mathrm{T}} \boldsymbol{M} \boldsymbol{\Phi}} \ddot{d}_{\mathrm{b}}=-\frac{\boldsymbol{\Phi}^{\mathrm{T}} \boldsymbol{M} \boldsymbol{J}}{\boldsymbol{\Phi}^{\mathrm{T}} \boldsymbol{M} \boldsymbol{\Phi}} a(t) \\
\boldsymbol{J}^{\mathrm{T}} \boldsymbol{M} \boldsymbol{\Phi} \ddot{\boldsymbol{\eta}}+\left(\boldsymbol{J}^{\mathrm{T}} \boldsymbol{M} \boldsymbol{J}+m_{\mathrm{b}}\right) \ddot{d}_{\mathrm{b}}+f=-\left(\boldsymbol{J}^{\mathrm{T}} \boldsymbol{M} \boldsymbol{J}\right) a(t)-m_{\mathrm{b}} a(t)
\end{gathered}
$$


where $\boldsymbol{\Phi}$ is the modal matrix corresponding to the first $q$ modes of vibration with dimensions $(n \times q), \boldsymbol{\nu}$ is the diagonal matrix of damping ratios and $\boldsymbol{\Omega}$ is the diagonal matrix of frequency. The terms $\ddot{\eta}_{k}$ and $\dot{\eta}_{k}$ in equation (96) and $\ddot{d}_{\mathrm{b}_{k}}$ in equation (97) can be expresed in function of the displacements $\eta_{k}$ and $d_{\mathrm{b} k}$ by applying, for example, the Newmark discretization presented in equations (89) and (90). The following problem, with the same characteristics as that described by the system of equations (93), is thus produced:

$$
\begin{gathered}
\boldsymbol{A}_{11}=\frac{1}{\beta \triangle t^{2}} \boldsymbol{I}+\frac{2 \gamma}{\beta \triangle t} \boldsymbol{\Omega}+\boldsymbol{\Omega}^{2} \quad \boldsymbol{A}_{12}=\frac{1}{\beta \triangle t^{2}} \boldsymbol{Q} \\
\boldsymbol{A}_{21}=\frac{1}{\beta \triangle t^{2}} \boldsymbol{J}^{\mathrm{T}} \boldsymbol{M \Phi} \quad \boldsymbol{A}_{22}=\frac{m_{\mathrm{tot}}}{\beta \triangle t^{2}}+\frac{\gamma}{\beta \triangle t} c_{\mathrm{b}}+k_{\mathrm{b}} \\
\boldsymbol{q}_{1}=\left[-a(t)+\frac{d_{\mathrm{b}_{k}}}{\beta \triangle t^{2}}+\frac{\dot{d}_{\mathrm{b}_{k}}}{\beta \triangle t}+\left(\frac{1}{2 \beta}-1\right) \ddot{d}_{\mathrm{b}_{k}}\right]+\frac{1}{\beta \triangle t^{2}} \boldsymbol{\eta}_{k}+\frac{2 \gamma}{\beta \triangle t} \boldsymbol{\Omega} \nu \boldsymbol{\eta}_{k}+ \\
\frac{1}{\beta \triangle t} \dot{\boldsymbol{\eta}}_{k}-2\left(1-\frac{\gamma}{\beta}\right) \boldsymbol{\Omega} \nu \dot{\boldsymbol{\eta}}_{k}+\left(\frac{1}{2 \beta}-1\right) \ddot{\boldsymbol{\eta}}_{k}-2\left(1-\frac{\gamma}{2 \beta}\right) \triangle t \boldsymbol{\Omega} \ddot{\boldsymbol{\eta}}_{k} \\
\boldsymbol{q}_{2}=\left[-a(t)+\frac{d_{\mathrm{b}_{k}}}{\beta \triangle t^{2}}+\frac{\dot{d}_{\mathrm{b}_{k}}}{\beta \triangle t}+\left(\frac{1}{2 \beta}-1\right) \ddot{d}_{\mathrm{b}_{k}}\right] m_{\mathrm{tot}}+\frac{1}{\beta \triangle t^{2}} \boldsymbol{J}^{\mathrm{T}} \boldsymbol{M} \boldsymbol{\Phi} \boldsymbol{\eta}_{k}+\frac{1}{\beta \triangle t} \boldsymbol{J}^{\mathrm{T}} \boldsymbol{M} \boldsymbol{\Phi} \dot{\boldsymbol{\eta}}_{k}+ \\
\left(\frac{1}{2 \beta}-1\right) \boldsymbol{J}^{\mathrm{T}} \boldsymbol{M} \boldsymbol{\Phi} \ddot{\boldsymbol{\eta}}_{k}+\frac{\gamma}{\beta \triangle t} c_{\mathrm{b}} d_{\mathrm{b}_{k}}-\left(1-\frac{\gamma}{\beta}\right) c_{\mathrm{b}} \dot{d}_{\mathrm{b}_{k}}-\left(1-\frac{\gamma}{2 \beta}\right) \Delta t c_{\mathrm{b}} \ddot{d}_{\mathrm{b}_{k}}-f
\end{gathered}
$$

where $\boldsymbol{Q}$ is a vector containing the modal participation factors and $\boldsymbol{\eta}_{k}, \dot{\boldsymbol{\eta}}_{k}$ and $\ddot{\boldsymbol{\eta}}_{k}$ are vectors containing know displacements, velocities and accelerations, respectivelly, at the time interval $k$. For example, for friction isolation, the nonlinear force $f$ is given in equation (8), with $c_{b}=0, k_{b}=0$ in equation (98b).

\section{Efficiency of the procedure}

The efficiency and convergence of the numerical block iteration schemes, applied to the problem of base isolated buildings has been studied by Barbat et al. (1996). A comparison is made between the monolithic Newmark method and the iterative block scheme for the case that considers the modal uncoupling of the system of equations of the structure (including the 10 modes of vibration) and it is shown in Figure 12 for a hysteretic base isolation system. The seismic excitation $a(t)$ has been defined in this case as a sinusoidal acceleration $a(t)=A \sin \theta t$ with an amplitude $A$ of $3.5 \mathrm{~m} / \mathrm{s}^{2}$ and a frequency $\theta$ of $10 \mathrm{rad} / \mathrm{s}$. The process of iterative blocks has a lower number of iterations throughout the calculation of the response of the system than the monolithic one.

Figure 13 shows the same comparison between the monolithic solution method and the iterative block for a frictional base isolation system. The results of Figure 13 correspond to the case of using prior modal uncoupling. Comparison of Figures 13 and 12 shows that the average number of iterations is similar for both types of bearings. Nevertheless, there is a greater variation in the number of iterations between calculation steps in the frictional case.

Figure 14 compares the variation of the residual norm for numerical simulations using iterative block schemes and monolithic solutions. This comparison is made at the step in which the maximum number of iteration occurres and considering frictional isolators. A tolerance of $1 \%$ in residual forces has been considered in the evaluation of the convergence of the iterative process. 


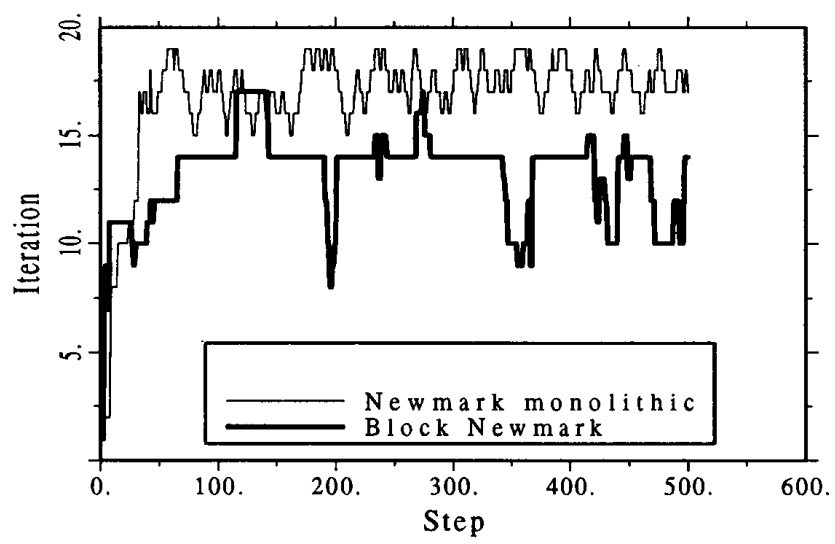

Figure 12. Total number of iterations in each step, structure with modal uncoupling (Newmark method), hysteretic NZ base isolation system

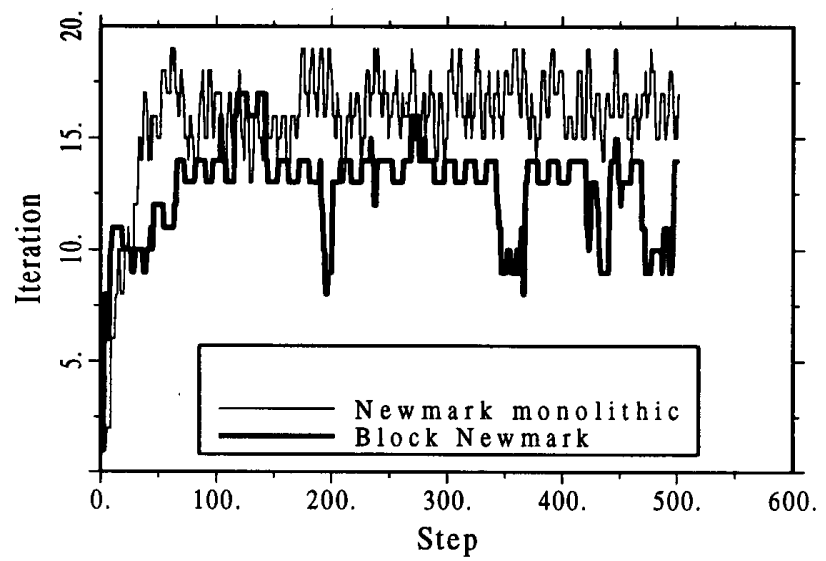

Figure 13. Total number of iterations in each step, structure with modal uncoupling (Newmark method), frictional case base isolation system

\section{SEISMIC RESPONSE COMPUTATIONS}

\subsection{Single Degree of Freedom, Elastic and Inelastic Building Response}

The aforementioned linear theory of base isolation indicates that, in general, base isolated buildings behave as rigid body systems concentrating the maximum displacements at the isolators. Consequently, single degree of freedom approximations are usefull to simulate their response, at least for preliminary design and for the purpose of comparing the performance of different isolation systems. For example, Figure 15 illustrates the maximum relative structural displacement for a single degree of freedom building subjected to El Centro ground motion, reported by Barbat et al. (1993) and Molinares and Barbat (1994). The figure presents the response for various isolation systems and for a conventional fix-base (FB) structure. The period in the figure corresponds to the fix-base structural one.

A first observation is that the relative structural displacements for a building equiped with any of the isolation sistems are considerably smaller than the corresponding displacements for a convetional fix-base structure and for the whole range of periods. The largest relative 


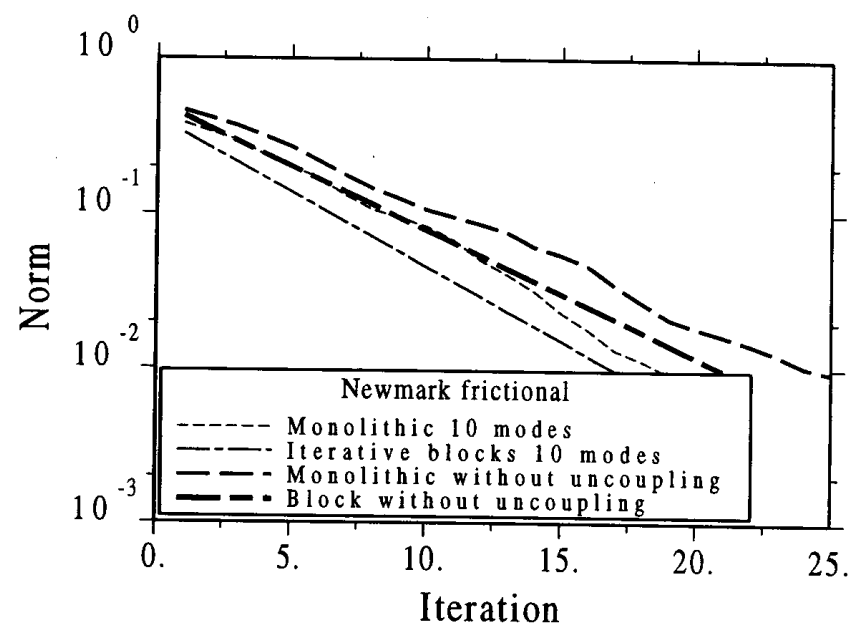

Figure 14. Variation of the residual norm, structure with frictional isolation (Newmark method)

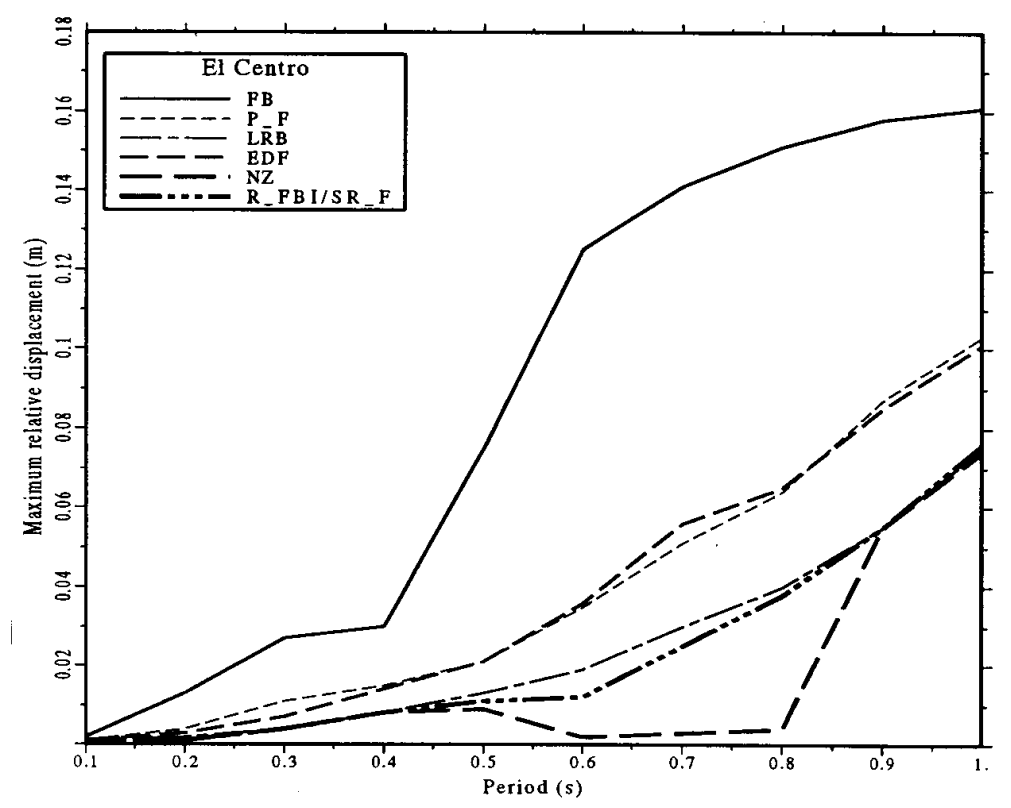

Figure 15. Maximum relative structural displacement

displacements among the isolated structures correspond to the friction and EDF systems. The smallest relative displacements correspond to the NZ system. The response for the buildings protected with R-FBI and SR-F systems is the same for the whole range of periods and it is represented by the same line in Figure 15. The similarity in response is because the El Centro ground motion does not induce the sliding of the upper steel plate from the SR-F system.

Figure 16 presents the maximum absolute structural acceleration for a single degree of freedom system supported on various isolation devices. The period in the figure corresponds to the fix-base structural one. The figure indicates that the acceleration is rather constant for 
the whole range of periods considered and it is considerably smaller than the corresponding fix-base (FB) aceleration. The structure with the friction device has the largest acelerations and the building with the NZ device has the smallest ones. The response for buildings equipped with NZ and LRB isolators is very similar, as it is the case of the EDF and R_FBI/SR_F systems.

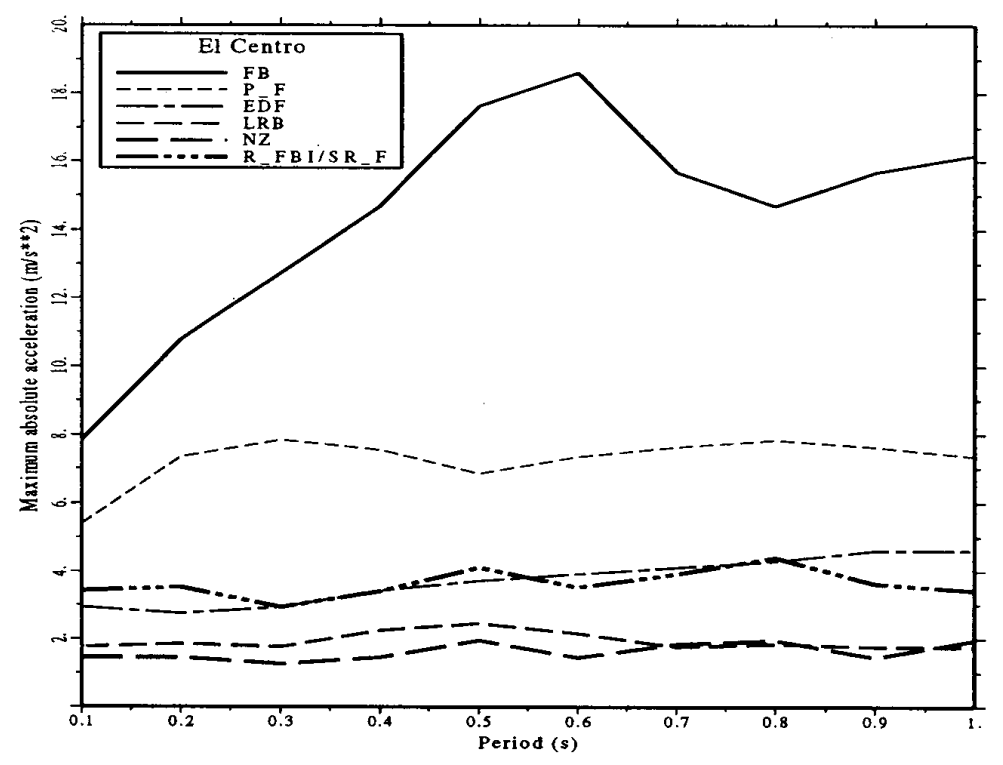

Figure 16. Maximum absolute aceleration

Figure 17 presents the maximum base displacement for isolated single degree of freedom structures supported on various isolation systems. The period in the figure corresponds to the fix-base case. The displacements present a rather jagged variation, altough in an average sense they may be considerated as constant for the whole range of structural periods. The smallest displacements correpond to the friction devices and the largest ones correspond to the LRB devices. The displacements for the NZ, EDF and R_FBI/SR_F systems are rather similar. Nevertheless, the base displacements are, in general, larger than the structural displacements presented in Figure 15, fact which confirm the rigid body assumption.

Usually the design criteria for a new base isolated building seeks to maintain the structure in the linear elastic range. The response of old weak buildings or the response of new buildings subjected to extreme earthquakes may not be, necesarily, in the aforementioned ideal elastic range. Therefore, a recent study investigate the relationships between the variation in friction coefficient and the response of sliding base isolated structures, in particular for low strength buildings, whose response may be in the nonlinear range (Bozzo and Barbat 1995). In the inelastic range, the influence of the sliding velocity on the friction coefficient may modify notoriously the behaviour of these weak structures and some results for such structures supported on sliding connections are given. The model incorporates variations in the friction coefficient caused by changes in the sliding velocity.

Using the rate dependent model, Bozzo and Barbat (1995) perform a simulation using a two degree of freedom model such as the one illustrated in Figure 11. Two cases were considered, one corresponds to an elastic structure and the other corresponds to an elastoplastic structure. The assumed strength in the latest case is $10 \%$ greater than the strength required to start the sliding. This case corresponds to a weak structure supported on sliding 


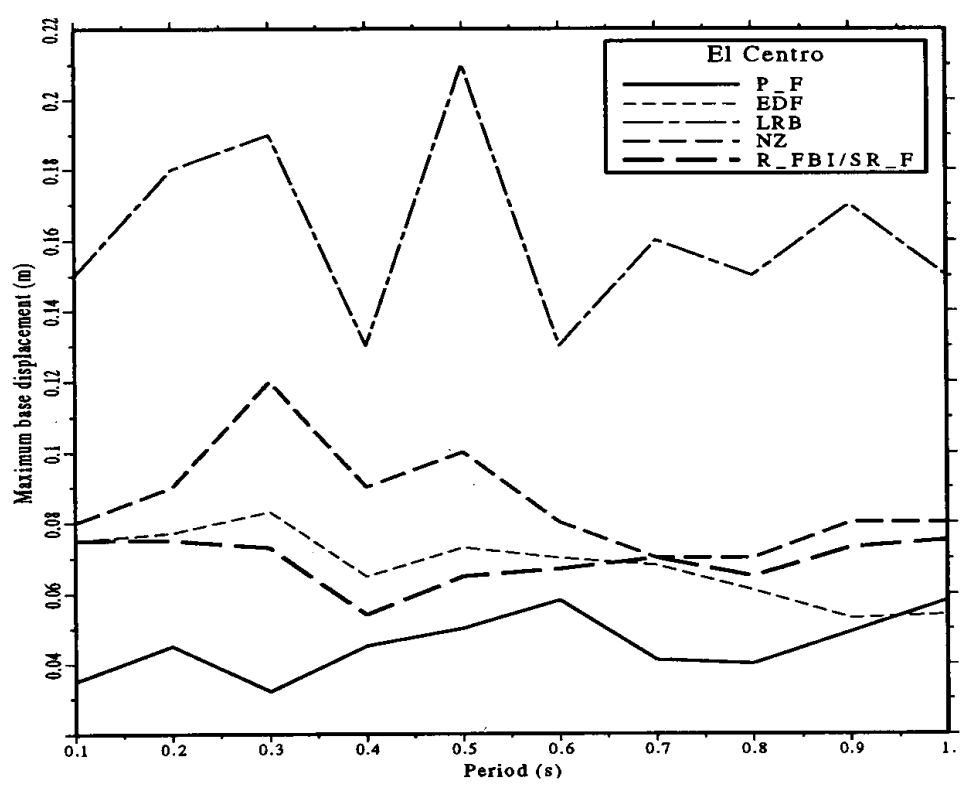

Figure 17. Maximum base displacement
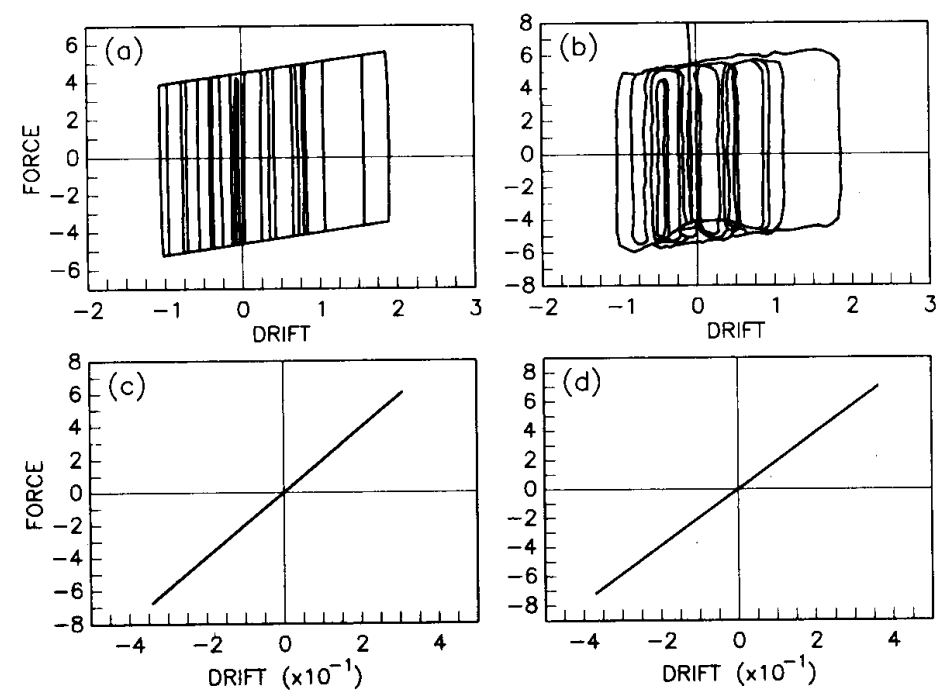

Figure 18. Time history response for elastic structures subjected to the NS component of the E1 Centro 1940 earthquake, $\xi=5 \%$. Elastic structural response. (a) Force-displacement isolator response (constant friction). (b) Force-displacement isolator response (variable friction). (c) Force-displacement structural response (constant friction). (d) Force-displacement structural response (variable friction)

connections, such as a building being retrofitted. The connection period in both cases is $3 \mathrm{~s}$. The constant friction coefficient selected corresponds to the minimum velocity-dependent value and the earthquake ground motion is the NS component of the El Centro 1940 record.

Figures 18 and 19 show the response for the linear elastic structure and the elasto-plastic structure, respectively. Each figure presents comparisons between the constant friction model and the velocity dependent model. Figure 18(a)-(d) indicates that the shear forces 
are not significantly varied between the constant and rate dependent models. For example, Figures 18(c) and 18(d) show that the maximum shear force in the structure for a constant friction model is very close to the similar value for the rate dependent model. Figure 18(b) shows that, in general, for long sliding displacements, the force decreases as compared to the constant friction model. This seems to be explained, since long sliding diplacements are asociated to higher velocities compared to small sliding displacements, and the velocity dependent model gives lower friction coefficients for larger velocities.

Figure 19 presents the response for the elasto-plastic systems. In this case there is a significant difference in response between the constant and velocity dependent friction models. For example, Figures 19(c) and 19(d) show that the maximum structure interstory drift for the constant friction model is increased three times as compared to the rate dependent model. Consequently, the structural ductility demand using the rate dependent model is three times the ductility demand using the minimum friction model. This can be explained since as the friction coefficient is increased, the sliding displacement is reduced. Taking into account that sliding base isolation reduces forces through energy dissipation, as the sliding displacement is reduced, larger ductility requirements in the structure should be expected.

Figure 20 presents response spectra generated for periods ranging between 0.1 and $1.0 \mathrm{~s}$. Figure 20(a) illustrates a shear forces spectrum and Figure 20(b) illustrates a ductility demand spectrum. The period of the sliding connection is $3 \mathrm{~s}$ and the typical El Centro NS 1940 record, corresponding to stiff local soil conditions, is considered. Figure 20(a) indicates that the shear forces for elastic structures are always increased using the rate dependent model compared to the minimum friction coefficient model. This increment is expected because the friction coefficient for the constant model is generally smaller than the friction coefficient for the rate dependent model. Nevertheless, the shear forces are always considerably smaller compared to those obtained in a linear structure and the difference between the friction models is not significant.
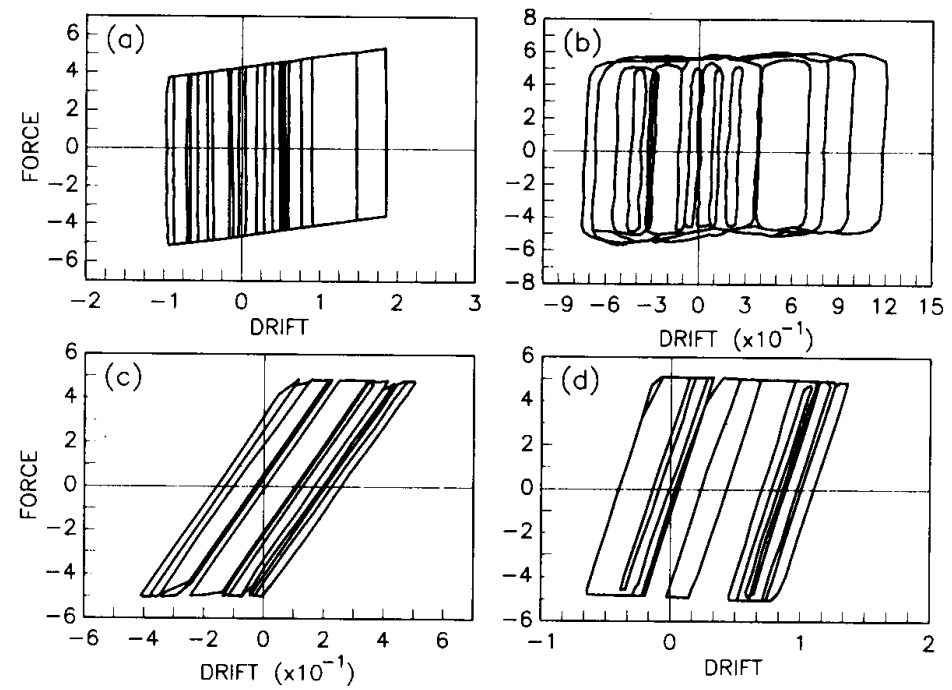

Figure 19. Time history response for inelastic structures subjected to the NS component of the El Centro 1940 earthquake, $\xi=5 \%$. (a) Force-displacement isolator response (constant friction). (b) Force-displacement isolator response (variable friction). (c) Force-displacement structural response (constant friction). (d) Force-displacement structural response (variable friction) 

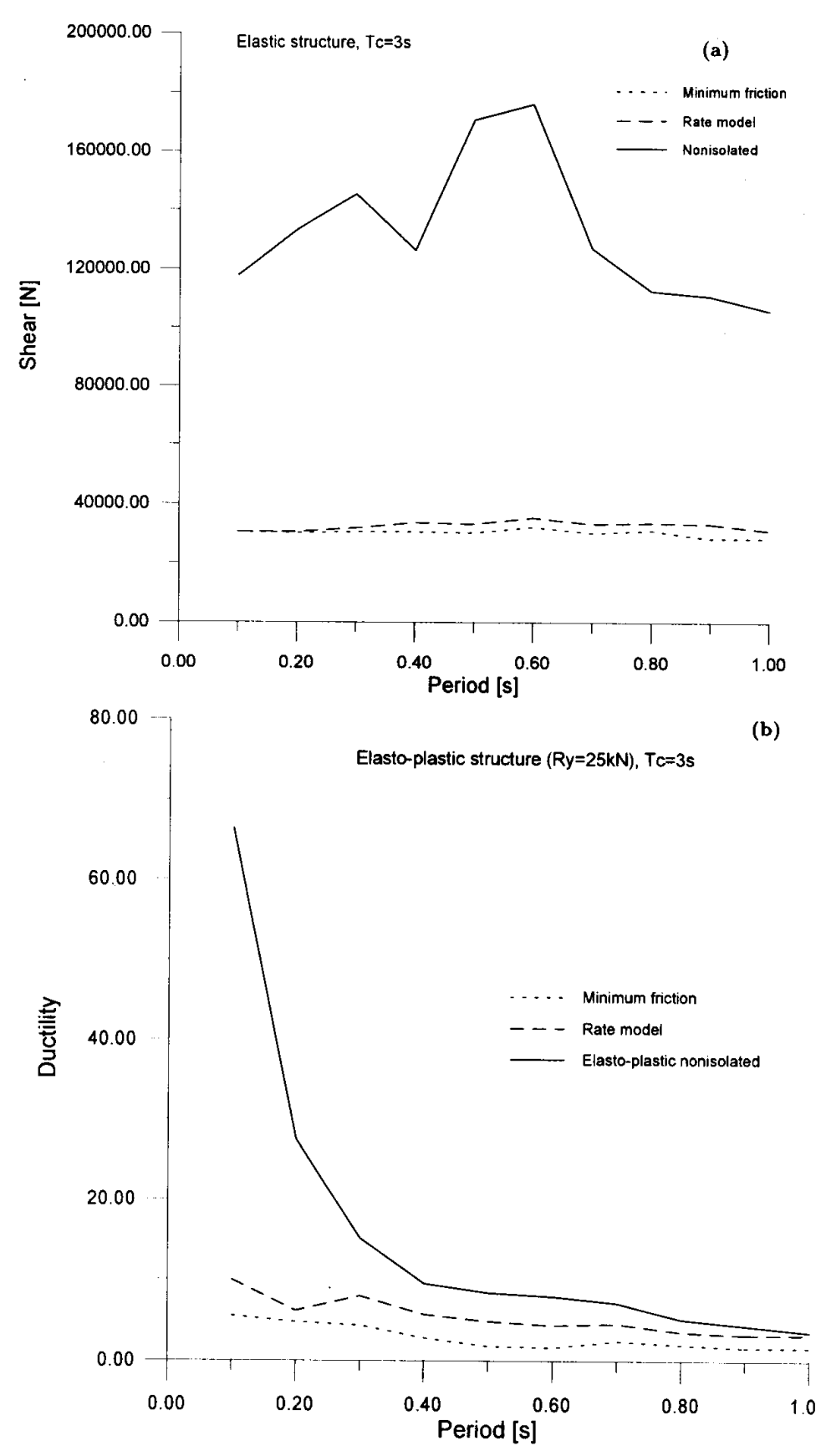

Figure 20. Response spectrums for structures subjected to the NS component of the El Centro 1940 earthquake, $\xi=5 \%$. (a) Base shear (elastic structures). (b) Structural ductility demands (inelastic structures)

For elasto-plastic structures, Figure 20(b) illustrates that the friction model is an important parameter regarding the ductility demands. For example, the ductility demand for a structure with a period equal to $0.6 \mathrm{~s}$ is increased more than two times, weather the model is based on a minimum friction or a rate dependent model. Furthermore, the benefits of sliding 
isolation in reducing ductility demands with respect to nonisolated structures is, in general, considerably reduced for elasto-plastic structures. Figure $17(\mathrm{~b})$ shows that a nonisolated inelastic structure, with a fundamental period larger than about $0.8 \mathrm{~s}$ has similar ductility demands than isolated structures modeled using the rate dependent model.

Apparently, the variation in the friction coefficient is important for weak elasto-plastic structures because the mass and damping forces are small at the connection level. By dynamic equilibrium, the equality between the shear force at the connection and at the columns is required. However, for these limited strength systems, the restoring force capacity is bounded by $R_{\mathrm{y}}$ and consequently the connection force and the sliding displacements are limited by $R_{\mathrm{y}}$. In other terms, if the isolated structure enters the inelastic range, the system tends to stop the sliding, consequently increasing the ductility requirements and structural drifts for the isolated building. This observation is conservative, since there is generally at least some deformation hardening in the columns.

\subsection{Multy Degree of Freedom Buildings}

Numerical simulations for multy degree of freedom buildings are performed in various studies (Way and Jeng 1988; Kircher and Lashkari 1989; Gadala 1991; Molinares and Barbat 1994). For example in Molinares and Barbat (1994) a shear building with ten stories and one degree of freedom in a horizontal direction is considered. The mass of each of the ten storeys, as well as that of the base, is the same. The structural stiffness of the columns diminishes with the story. The top story stiffness is half the stiffness of the base columns. The damping ratios have been fixed at 0.05 for all vibration modes. The earthquake ground motion corresponds to El Centro NS 1940 record. Figure 21 illustrates the isolator displacement for the ten story building. The figure compares the numerical response for an isolator using the Wen (1976) model, an elasto-plastic model and an equivalent linear model. The time histories between the models are quite different, although their maximum values are close. Figure 22 presents a similar comparison but for the structure relative top displacement.

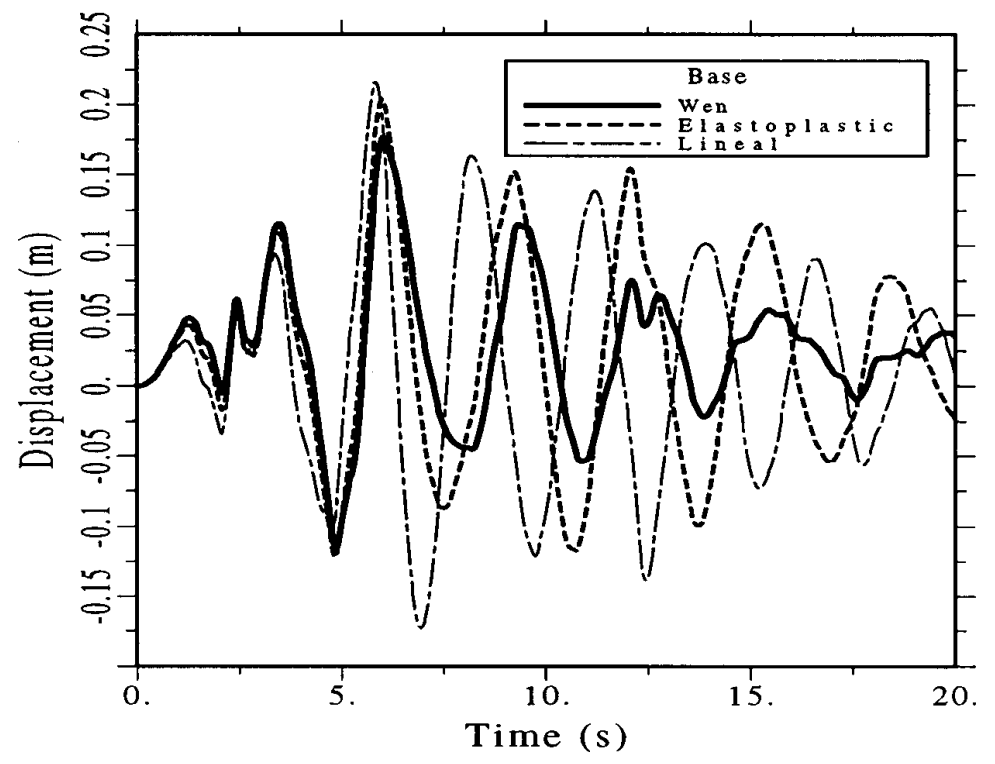

Figure 21. Isolator time history displacement response 


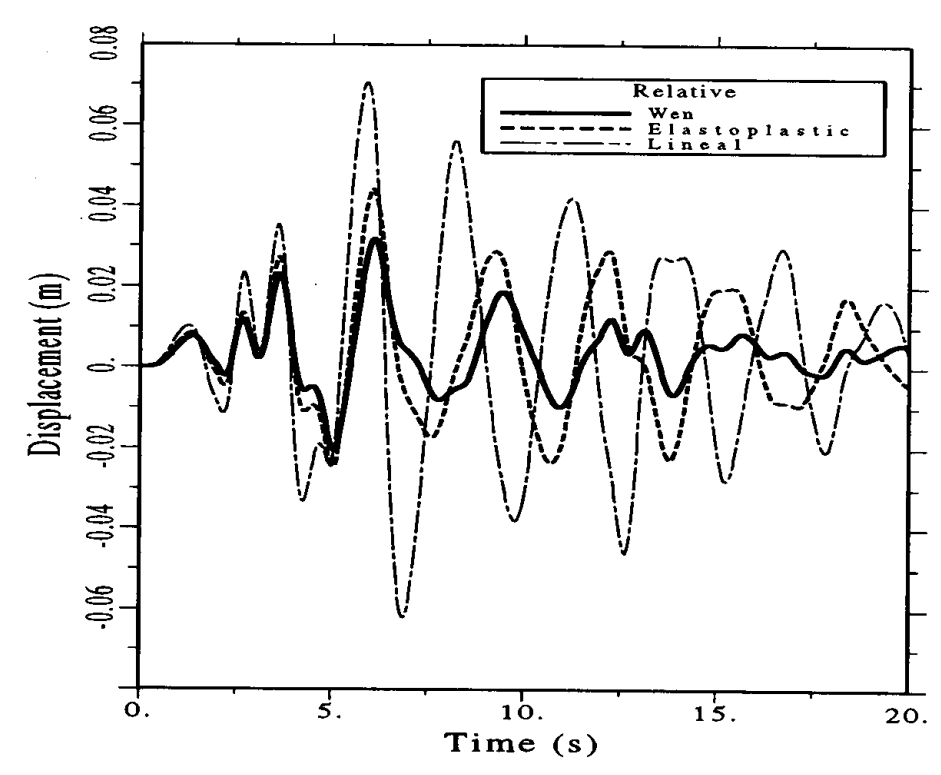

Figure 22. Relative top time history structural displacement

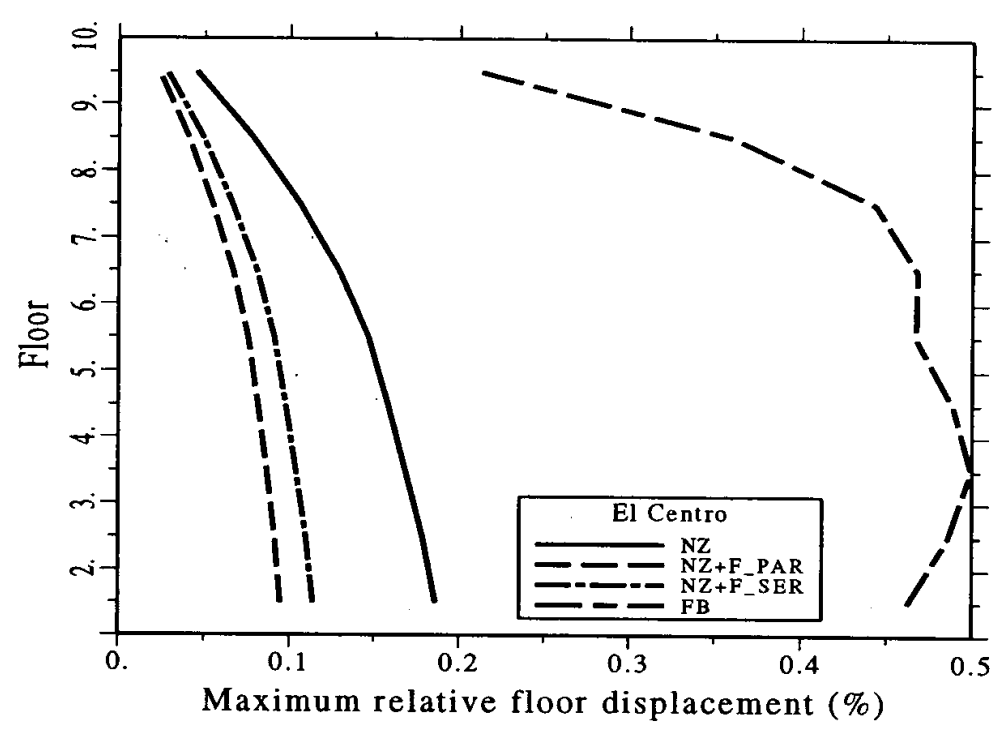

Figure 23. Maximum relative floor displacement

Figure 23 illustrates the story relative displacement for a building using the NZ system and the NZ system and friction added in series (NZ + F_ SER) and in parallel (NZ + F_ PAR), both illustrated in Figure 24. The displacements correspond to the floor structural drift expresed as a percentage of the story height. The figure indicates that the structural drift does not change significantly with the story for the different isolators considered. The drift for the protected structures is much smaller than the corresponding one for the fix-base structure. The smallest structural drifts correspond to the building using the NZ system plus friction in parrallel. The largest structural drifts correspond to the building using the NZ system. The average result corresponds to a building protected using the NZ system with friction added in series. 


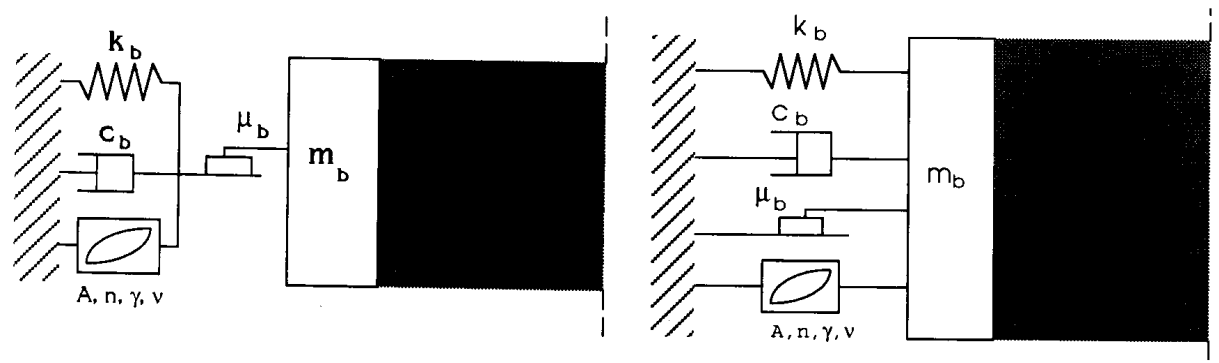

Figure 24. (a) $\left(\mathrm{NZ}+\mathrm{F}_{-} \mathrm{SER}\right)$ and (b) $\left(\mathrm{NZ}+\mathrm{F}_{-} \mathrm{PAR}\right)$

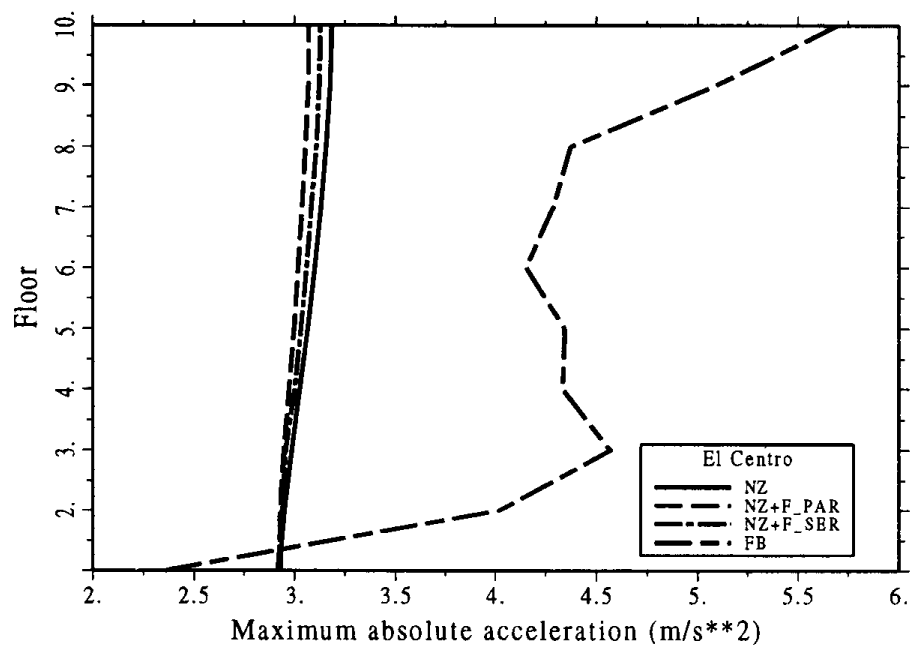

Figure 25. Absolute floor aceleration

Figure 25 presents the absolute story aceleration for a building using the NZ system and the NZ system with friction added in series (NZ + F_ SER) and in parallel (NZ + F_ PAR). The aceleration is nearly constant with height and its relative values is similar for the various isolators considered. The fix-base aceleration is considerably larger that the corresponding one for the isolated buildings.

\section{CONCLUSIONS}

The paper presents an extensive overview of numerical simulation techniques proposed for the dynamic analysis of base isolated buildings. Analytical expresions for the nonlinear restitutive forces corresponding to various isolation systems, are given. Monolithic integration of the equations of motion, static condensation and block iterative techniques are discussed for the numerical analysis of these structures. The numerical experiments show that convergence improves when block iterative methods are used. For the block iterative scheme, the resulting algorithm has a linear convergence rate, with a slope steeper than using the monolithic one. Static condensation techniques are also usefull for the analysis of these structures, since the nonlinearities are usually concentrated at the base.

In general, the seismic response of buildings using any of the existing base isolation systems is considerably improved compared to a conventional fix base design. For frictional 
base isolation systems, a constant mimimum friction coefficient model generally provided an upper bound to total sliding displacements and a lower bound to structural drifts, compared to a rated dependent friction model. For inelastic structural response, the constant friction model provided a lower, unconservative, bound for the ductility demands. The difference is considerably more important for weak structures - such as retrofitted ones - compared to ideally elastic models. Consequently, it is fundamental to consider a realistic friction model, particularly for weak structures, whose response may be in the inelastic range. Variations in ductility demands due to changes in friction coefficient are not linearly dependent.

Finally, the paper includes an extense set of references, covering specially the last ten years. The passive control of buildings includes base isolation and energy dissipation devices, but this work deals only with base isolation. Energy dissipation devices have received much attention in the recent years and there are many experimental as well as some analytical studies, about their dynamic response. It is expected that in the future this technique will be use more frecuently.

\section{ACKNOWLEDGEMENTS}

The second author wish to thank the "Visiting Professor" position from the "Generalitat de Catalunya". The work has been also supported by the "Dirección General de Investigación Científica y Técnica" (DGICYT) of the Spanish Government under the Grant No. PB93-1040.

\section{REFERENCES}

Ali, H.E. and Abdel-Ghaffer, A. (1995), "Modeling of rubber and lead passive-control bearings for seismic analysis", Journal of Structural Engineering, 121(7).

Amin, N. and Mokha, A. (1995), "Base isolation gets its day in court", Civil Engineering, (2), 44-47.

Arnold, C. (1984), "Soft first stories: Truths \& myths", Eighth World Conference on Earthquake Engineering, San Francisco, 5, 943-950.

Barbat, A.H. and Canet, J.M. (1994), Estructuras Sometidas a Acciones Sismicas, segunda edición, Centro Internacional de Métodos Numéricos en Ingeniería, Barcelona.

Barbat, A.H., Molinares, N. and Canas, J.A. (1993), "Simulación de sistemas de apoyo antisísmico con comportamiento no lineal", II Congreso de Métodos numéricos en Ingeniería, Navarrina F. and Casteleiro M., editors, Sociedad Española de Métodos Numéricos en Ingeniería (SEMNI), 359-368.

Barbat,A.H., Molinares, N. and Codina, R. (1996), "Effectiveness of block iterative schemes in computing the seismic response of buildings with nonlinear base isolation", Computers and structures, 58(1), 133-141.

Bozzo, L.M. and Barbat, A.H. (1995), "Nonlinear response of structures with sliding base isolation", Journal of Structural Control, 2(2), 59-77.

Bozzo, L.M. and Mahin, S. (1990) "Design of Frictional Base Isolation Systems", $4^{\text {th }}$ US National Conference on Earthquake Engineering, Palm Springs, California.

Buckle, I.G. and Mayes, R.L. (1990), "Seismic isolation: history, applications, and performance a world view", Earthquake Spectra, 6(2), 161-202.

Caspe, M.S. (1970), "Earthquake isolation of multi-story concrete structures", Journal of the American Concrete Institute, 923-933, 11.

Caspe, M.S. (1984), "Base isolation from earthquake hazards, an idea whose time has come!", Eighth World Conference on Earthquake Engineering, San Francisco, 5, 1031-1038. 
Caspe, M.S. and Reinhorn, A.M. (1986), "The earthquake barrier. A solution for adding ductility to otherwise brittle buildings", Proceedings of ATC-17 Seminar on Base Isolation and Passive Energy Dissipation, San Francisco, California, 331-342.

Codina, R. (1992), "A Finite Element Model for Incompressible Flow Problems", Doctoral Dissertation, Universidad Politécnica de Cataluña, Barcelona.

Constantinou, M.C., Mokha, A. and Reinhorn, A.M. (1990), "Teflon Bearings in Base Isolation II: Modeling", Journal of Structural Engineering, ASCE, 116(2), 455-474.

Constantinou, M.C., Mokha, A.S. and Reinhorn, A.M. (1990), Experimental and Analytical Study of a Combined Sliding Disc Bearing and Helical Steel Spring Isolation System, Report NCEER-90-0019, National Center for Earthquake Engineering Research, State University of New York, Buffalo.

Constantinou, M.C. and Tadjbakhsh, I.G. (1984), "The optimum design of a base isolation system with frictional elements", Earthquake Engineering and Structural Dynamics, 12, 203-214.

Chalhoub, M.S. and Kelly, J.M. (1989), "Sliders and tension controlled reinforced elastomeric bearings combined for earthquake isolation", Earthquake Engineering and Structural Dynamics, 19, 333344.

Derham, C.J. (1986), "Nonlinear natural rubber bearings for seismic isolation", ATC-17, Seminar on Base Isolation and Passive Energy Dissipation, California.

Dorka, U.G. (1994), "Friction devices for Earthquake Protection of Buildings", $10^{\text {th }}$ European Conference on Earthquake Engineering, Vienna.

Dowrick, D.J., Cousins, W.J., Robinson, W.H. and Babor, J. (1992), "Recent developments in seismic isolation in New Zealand", Proceedings of the Tenth World Conference on Earthquake Engineering, Madrid, Spain, 4, 2305-2309.

Fan Fa-Gung, Ahmadi, G. and Tadjbakhsh, I.G. (1988), Base Isolation of a Multi-Story Building Under a Harmonic Ground Motion. A Comparison of Performances of Various Systems, Report NCEER-88-0010, National Center for Earthquake Engineering Research, State University of New York, Buffalo.

Fintel, M. and Khan, R.F. (1969), "Shock absorbing soft story concept for multistory earthquake structures", Journal of the American Concrete Institute, 66-29, 318-390.

Fujita, T., Suzuki, S. and Fujita, S. (1989), "Hysteretic restoring force characteristics of high damping rubber bearings for seismic isolation", ASME Pressure Vessels and Piping Conference, Hawai, PVP181, 23-28.

Gadala, M.S. (1991), "Unified numerical treatment of hyperelastic and rubber-like constitutive laws", Communications in Applied Numerical Methods, 7, 581-587.

Griffith, M.C., Aiken, I.D. and Kelly, J.M. (1990a), "Comparison of earthquake simulator test results with SEAONC tentative seismic isolation design requirements", Earthquake Spectra, 6(2), 403-418.

Griffith, M.C., Aiken, I.D. and Kelly, J.M. (1990b), "Displacement control and uplift restrain for base-isolated structures", Journal of Structural Engineering, ASCE, 116(4).

Griffith, M.C., Kelly, J.M. and Aiken, I.D. (1988a), Experimental Evaluation of Seismic Isolation of a Nine-Story Braced Steel Frame Subject to Uplift, Report EERC-88/05, Earthquake Engineering Research Center, University of California, Berkeley.

Griffith, M.C., Kelly, J.M., Coveney, V.A. and Koh, C.G. (1988b), Experimental Evaluation of Seismic Isolation of Medium-Rise Structures Subject to Uplift, Report EERC-88/02, Earthquake Engineering Research Center, University of California, Berkeley.

Guerand, R., Noel-Leronx, J.P., Livolant, M. and Michalopoulos, A.P. (1985), "Seismic isolation using sliding-elastomer bearing pads", Nuclear Engng. and Design, 84, 363-377. 
Hadjian, A.H. and Tseng, W.S. (1986), "A Comparative Evaluation of Passive Seismic Isolation Schemes", Base Isolation and Passive Energy Dissipation, C. Rojahn, editor, ATC-17, National Bureau of Standards, 291-304.

Ikonomou, A.S. (1985), "Alexisismon isolation engineering for nuclear power plants", Nuclear Engineering and Design, 85, 201-216.

Jané, L. and Barbat, A.H. (1992), Estructuras de edificación con aislamiento antisísmico, Monografía 13, Centro Internacional de Métodos Numéricos en Ingeniería, Barcelona.

Kelly, J.M. (1993), Earthquake-resistant design with rubber, Springer-Verlag, London.

Kelly, J.M. (1980), Testing of a Natural Base Isolation System by an Explosively Simulated Earthquake, Report EERC-80/25, Earthquake Engineering Research Center, University of California, Berkeley.

Kelly, J.M. (1983a), "Recent developments in aseismic base isolation", Symposium on Base Isolation of Structures, ASCE, Philadelphia.

Kelly, J.M. (1983b), The Economic Feasibility of Seismic Rehabilitation of Buildings by Base Isolation, Report EERC-83/01, Earthquake Engineering Research Center, University of California, Berkeley.

Kelly, J.M. (1986), "Aseismic base isolation: Rewiew and bibliography", Soil Dynamics and Earthquake Engineering, 5(3), 202-216.

Kelly, J.M. (1991), "Base isolation: Linear theory and design", Earthquake Spectra, 7(2), 301-323.

Kelly, J.M. (1991), "Base isolation: Origins and development", Bulletin of the Earthquake Engineering Research Center, University of California, Berkeley, 12(1).

Kelly, J.M. and Aiken, I.D. (1989), "Recent developments in testing base isolation systems", Proceedings, Seventh ASCE Structures Congress, American Society of Civil Engineers, San Francisco, California.

Kelly, J.M. and Beucke, K.E. (1983), "A friction damped base isolation system with fail safe characteristics", Earthquake Engineering and Structural Dynamics, 11, 33-56.

Kelly, J.M. and Tsai, H.C. (1984), Seismic Response of Light Internal Equipment in Base Isolated Structures, Report EERC-84/17, Earthquake Engineering Research Center, University of California, Berkeley.

Keowen, S., Amin, N., Mokha, A. and Ibanez, P. (1994), "Vibration Study of the U.S. Court of Appeals Building for Seismic Isolation Retrofit", First World Conference on Structural Control, California.

Kircher, C.A. and Lashkari, B. (1989), Statistical evaluation of nonlinear response of seismic isolation systems, Report JBA 109-070, 1, Jack R. Benjamin \& Associates, Inc., Consulting Engineers, California.

Kirikov, B. (1992), History of Earthquake Resistant Construction, Instituto de Ciencias de la Construcción Eduardo Torroja, Madrid.

Koh, C.G. and Balendra, T. (1989), "Seismic response of base isolated buildings including $P-\Delta$ effects of isolation bearings", Earthquake Engineering and Structural Dynamics, 18, 461-473.

Koh, C.G. and Kelly, J.M. (1986), Effects of Axial Load on Elastomeric Isolation Bearings, Report EERC-86/12, Earthquake Engng. Research Center, Univ. of California, Berkeley.

Kwok, K. (1984), "Damping increase in building with tuned mass dampers, Journal of Engineering Mechanics Division, ASCE, 110(11), 1645-1649. 
Leger, P., Wilson, E. and Clough, R. (1986), The use of load dependent vectors for dynamic and earthquake analysis, Report EERC-86/04, Earthquake Engineering Research Center, University of California, Berkeley.

Lin, B.C., Tadjbakhsh, I.G., Papageorgiou, A.S. and Ahmadi, G. (1989), "Response of base-isolated buildings to random excitations described by the Clough-Penzien spectral model", Earthquake Engineering and Structural Dynamics, 18, 49-62.

Li, L. (1984), "Base isolation measure for aseismic buildings in China", Eighth World Conference on Earthquake Engineering, San Francisco, California, 6, 791-798.

Mokha, A.S., Constantinou, M.C. and Reinhorn, A.M. (1988), Teflon Bearings in Aseismic Base Isolation: Experimental Studies and Mathematical Modeling, Report NCEER-88-0038, National Center for Earthquake Engng. Research, State University of New York, Buffalo.

Mokha, A.S., Constantinou, M.C. and Reinhorn, A.M. (1990), Experimental Study and Analytical Prediction of Earthquake Response of a Sliding Isolation System with a Spherical Surface, Report NCEER-90-0020, National Center for Earthquake Engineering Research, State University of New York, Buffalo.

Molinares, N. and Barbat, A.H. (1994), Edificios con aislamiento de base no lineal, Monografías de ingeniería sísmica, $\mathbf{5}$, Centro internacional de métodos numéricos en ingeniería.

Mostaghel, N. (1984), Resilient-Friction Base Isolator, Report UTEC 84-097, Univ. of Utah.

Mostaghel, N., Hejazi, M. and Khodaverdian, M. (1986), "Response of structures supported on resilient-friction base isolator", Proceeding 3th U. S. National Conference on Earthquake Engineering, Charleston, South Carolina, 1993-2003.

Mostaghel, N. and Khodaverdian, M. (1987), "Dynamics of resilient-friction base isolator (R-FBI)", Earthquake Engineering and Structural Dynamics, 15, 379-390.

Mostaghel, N. and Kelly, J.M. (1987), Design Procedures for R-FBI Bearings, Report No. EERC87/18, Earthquake Engineering Research Center, University of California, Berkeley.

Mostaghel, N. and Khodaverdian, M. (1988), "Seismic response of structures supported on R-FBI system", Earthquake Engineering and Structural Dynamics, 16, 839-854.

Mostaghel, N. and Tanbakuchi, J. (1983), "Response of sliding structures to earthquake support motion", Earthquake Engineering and Structural Dynamics, 11, 729-748.

McKay, G.R., Chapman, H.E. and Kirkcaldie, D.K. (1990), "Seismic isolation: New Zealand applications", Earthquake Spectra, 6(2), 203-222.

Nagarajaiah, S., Reinhorn, A.M. and Constantinou, M.C. (1991), 3D-BASIS - Nonlinear Dynamic Analysis of Three-Dimensional Base Isolated Structures: Part II, Report NCEER-91-0005, National Center for Earthquake Engineering Research, State University of New York at Buffalo.

Nagashima, I., Kawamura, S., Kitazawa, K. and Hisano, M. (1987), "Study on a base isolation system", Proceedings of the Third Conference on Soil Dynamics and Earthquake Engineering, Princeton University.

Pan, T.C. and Cui, W. (1994), "Dynamic characteristics of shear buildings on laminated rubber bearings", Earthquake Engineering and Structural Dynamics, 23, 1315-1329.

Pinto, P.E. and Vanzi, I. (1992), "Base-isolation: Reliability for different design criteria", Proceedings of the Tenth World Conf. on Earthquake Engng., Madrid, 4, 2033-2038.

Robinson, W.H. (1982), "Lead-rubber hysteretic bearings suitable for protecting structures during earthquakes", Earthquake Engineering and Structural Dynamics, 10, 593-604. 
Rodwell, E., Ehrman, C.S., Maeno, Y., Sigal, G.B. y Womack, G..J. (1990), "Electric power research institute contribution to international utility industry seismic isolation development program", Earthquake Spectra, 6(2).

SEAOC (1990), Structural Engineering Association of California, "Tentative general requirements for the design and construction of seismic isolated structures", Appendix IL of Reccomended Lateral Force Requirements and Commentary Blue Book, California.

Shustov, V. (1992), "Base isolation: Fresh insight", Proceedings of the Tenth World Conference on Earthquake Engineering, Madrid, Spain, 4, 1983-1986.

Skinner, R.I., Robinson, W.H. and McVerry, G.H. (1993), An Introduction to Seismic Isolation, John Wiley \& Sons, Chichester.

Skinner, R.I., McVerry, G.H. and Robinson, W.H. (1992), "Developments in understanding, analysing and designing structures with aseismic isolation", Proceedings of the Tenth World Conference on Earthquake Engineering, Madrid, Spain, 4, 1977-1982.

Skinner, R.I., Kelly, J.M. and Heine, A.J. (1975), "Hysteric dampers for earthquake-resistant structures", Earthquake Engineering and Structural Dynamics, 3, 287-296.

SMIRT11 (1991a), "Base isolation and vibration control systems" in Seismic Isolation and Response Control for Nuclear and Non-Nuclear Structures, SMIRT 11, Tokyo, 137-148.

SMIRT11 (1991b), "Seismic isolation and vibration control system" in Seismic Isolation and Response Control for Nuclear and Non-Nuclear Structures, SMIRT 11, Tokyo, 85-92.

SMIRT11 (1991c), "Rubber technology for seismic isolation", en Seismic Isolation and Response Control for Nuclear and Non-Nuclear Structures, SMIRT 11, Tokyo, 45-56.

Su, L., Ahmadi, G. and Tadjbakhsh, I.G. (1989), "A comparative study of performances of various base isolation systems. Part I: Shear beam structures", Earthquake Engineering and Structural Dynamics, 18, 11-32.

Su, L., Ahmadi, G. and Tadjbakhsh, I.G. (1990), "A comparative study of performances of various base isolation systems. Part II: Sensitivity analysis", Earthquake Engineering and Structural Dynamics, 19, 21-33.

Tajirian, F.F., Kelly, J.M. and Aiken, I.D. (1990a), "Seismic isolation for advanced nuclear power stations", Earthquake Spectra, 6(2), 371-402.

Tajirian, F.F., Kelly, J.M., Aiken, I.D. and Veljovich, W. (1990b), "Elastomeric bearings for threedimensional seismic isolation", ASME PVP Conference, Nashville, Tennessee.

Tajirian, F.F. and Kelly, J.M. (1987), "Seismic and shock isolation system for mo dular power plants", The 1987 Pressure Vessels and Piping Conference, California.

Tsopelas, P. and Constantinou, M.C. (1994), NCEER-Taisei Corporation Research Program on Sliding Seismic Isolation Systems for Bridges: Experimental and Analytical Study of a System Consisting of Sliding Bearings and Fluid Restoring Force/Damping Devices, Report NCEER-94-0014, National Center for Earthquake Engineering Research, State University of New York at Buffalo.

Way, D. and Jeng, V. (1988), "NPAD - A computer program for the analysis of base isolated structures", ASME Pressure Vessels and Piping Conference, Pennsylvania, PVP-147, 65-94.

Way, D. and Howard, J. (1990), "Seismic rehabilitation of the Mackay School of Mines, Phase III, with base isolation", Earthquake Spectra, 6(2), 297-308.

Way, D. and Howard, J. (1992), "Rehabilitation of the Mackay School of Mines, Phase III, with base isolation", Proceedings of the Tenth World Conf. on Earthquake Engineering, Madrid, Spain, 4, 2027-2031. 
Wen, Y.K. (1976), "Method for random vibration of hysteretic systems", Journal of the Engineering Mechanics Division, ASCE, 102, 249-263.

Zayas, V.A., Low, S., Bozzo, L.M. and Mahin S. (1989), Feasibility and Performance Studies on Improving the Earthquake Resistance of New and Existing Buildings using the Friction Pendulum Base Isolation System, Report UCB-EERC 89-09, Earthquake Engineering Reserach Center, University of California at Berkeley.

Zayas, V.A., Low, S.S. and Mahin, S.A. (1988), The FPS Earthquake Resisting System: Experimental Report, Report EERC-87/01, 16, Earthquake Engineering Research Center, University of California, Berkeley, 839-854.

Zayas, V.A., Low, S.S. and Mahin, S.A. (1990), "A simple pendulum technique for achieving seismic isolation", Earthquake Spectra, 6(2), 317-334.

Please address your comments or questions on this paper to:

International Center for Numerical Methods in Engineering

Edificio C-1, Campus Norte UPC

Gran Capitán s/n

08034 Barcelona, Spain

Phone: 34-3-4016035; Fax: 34-3-4016517 